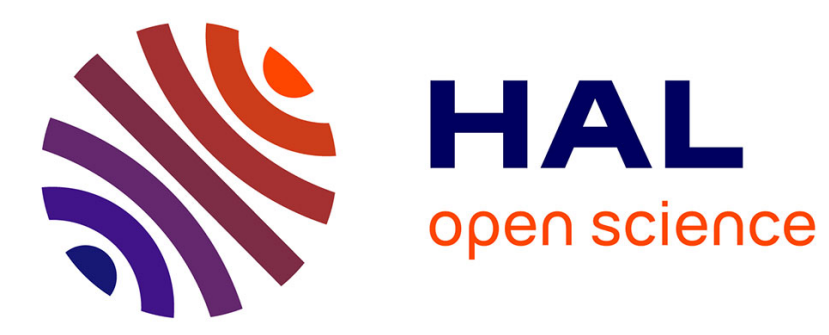

\title{
Heat transfer simulation in a thermochemical solar reactor based on a volumetric porous receiver
}

\author{
H.I. Villafán-Vidales, Stéphane Abanades, Cyril Caliot, H. Romero-Paredes
}

\section{To cite this version:}

H.I. Villafán-Vidales, Stéphane Abanades, Cyril Caliot, H. Romero-Paredes. Heat transfer simulation in a thermochemical solar reactor based on a volumetric porous receiver. Applied Thermal Engineering, 2011, 31 (16), pp.3377. 10.1016/j.applthermaleng.2011.06.022 . hal-00789864

\section{HAL Id: hal-00789864 https://hal.science/hal-00789864}

Submitted on 19 Feb 2013

HAL is a multi-disciplinary open access archive for the deposit and dissemination of scientific research documents, whether they are published or not. The documents may come from teaching and research institutions in France or abroad, or from public or private research centers.
L'archive ouverte pluridisciplinaire HAL, est destinée au dépôt et à la diffusion de documents scientifiques de niveau recherche, publiés ou non, émanant des établissements d'enseignement et de recherche français ou étrangers, des laboratoires publics ou privés. 


\section{Accepted Manuscript}

Title: Heat transfer simulation in a thermochemical solar reactor based on a volumetric porous receiver

Authors: H.I. Villafán-Vidales, Stéphane Abanades, Cyril Caliot, H. Romero-Paredes

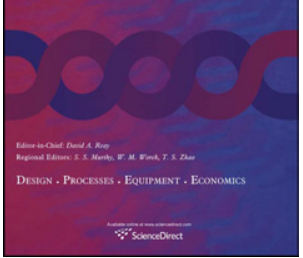

PII:

S1359-4311(11)00332-2

DOI:

10.1016/j.applthermaleng.2011.06.022

Reference: ATE 3617

To appear in: Applied Thermal Engineering

Received Date: 25 February 2011

Revised Date: 12 May 2011

Accepted Date: 14 June 2011

Please cite this article as: H.I. Villafán-Vidales, S. Abanades, C. Caliot, H. Romero-Paredes. Heat transfer simulation in a thermochemical solar reactor based on a volumetric porous receiver, Applied Thermal Engineering (2011), doi: 10.1016/j.applthermaleng.2011.06.022

This is a PDF file of an unedited manuscript that has been accepted for publication. As a service to our customers we are providing this early version of the manuscript. The manuscript will undergo copyediting, typesetting, and review of the resulting proof before it is published in its final form. Please note that during the production process errors may be discovered which could affect the content, and all legal disclaimers that apply to the journal pertain. 


\title{
Heat transfer simulation in a thermochemical solar reactor based on a
}

\section{volumetric porous receiver}

\section{H.I.Villafán-Vidales ${ }^{\mathrm{a}}$, Stéphane Abanades ${ }^{\mathrm{a}, *}$, Cyril Caliot $^{\mathrm{a}}$, H. Romero-Paredes}

${ }^{a}$ Processes, Materials and Solar Energy Laboratory, PROMES-CNRS, 7 Rue du Four Solaire, 66120

Font-Romeu, France

${ }^{b}$ Departamento de Ingeniería de Procesos e Hidráulica, Universidad Autónoma MetropolitanaIztapalapa, Av. San Rafael Atlixco No.186, 09340, México D.F, México

${ }^{*}$ Corresponding author. Tel.: +3346830 77 30; Fax: +33468302940

E-mail address: stephane.abanades@promes.cnrs.fr

\begin{abstract}
A $1 \mathrm{~kW}$ thermochemical solar reactor/receiver fitted with a porous ceramic foam structure is studied numerically to predict the thermal transfers inside the volumetric solar receiver. This reactor is devoted to the production of hydrogen from two-step thermochemical cycles based on mixed metal oxides, and it features a porous media coated with the reactive ferrite material $\left(\mathrm{M}_{\mathrm{x}} \mathrm{Fe}_{3-\mathrm{x}} \mathrm{O}_{4}\right)$ that is directly irradiated by concentrated solar energy. The developed numerical model couples the fluid flow, heat and mass transfer, and the chemical reactions. The FLUENT code solves the transport equations of the fluid phase. The source terms of the solid phase, radiative heat transfer and chemical reactions are then computed using user-defined functions. The complete model was used to predict the thermal behaviour of the receiver under different operational conditions, which concerns the inert gas flow rate, the incident solar flux, the porosity, the mean cell size of the foam, the length of the volumetric solar
\end{abstract}


receiver, and the influence of the chemical reactions. Results show that the maximal temperature of the foam is around $1710 \mathrm{~K}$ with $6 \mathrm{~L}_{\mathrm{n}} / \mathrm{min} \mathrm{N}_{2}$ for a mean solar concentration of 1040 suns. The higher the gas flow rate, the lower the temperature of the foam. The suitable operating conditions were defined for carrying out the reduction and hydrolysis reactions in the whole reactor volume at $1400 \mathrm{~K}$ and $1200 \mathrm{~K}$, respectively. A model validation was performed with experimental data obtained from the reactor testing at the focus of a solar furnace.

\section{Keywords}

Porous media, ferrite, hydrogen production, solar reactor, ceramic foam, volumetric receiver

\section{Nomenclature}

$c_{p}$

$d_{s}$

$E_{a}$

$G d$

$H$

$h$

$I_{b \eta}$

$I_{\eta}$

$J$

$\mathrm{L}_{\mathrm{n}}$

$M_{i}$

$\dot{m}_{g}$

$\overrightarrow{\mathbf{n}}$

$q^{\prime \prime \prime}$

$R$

$R_{g}$

$\operatorname{Re}$

$\hat{\mathbf{s}}$

$\mathrm{S}$

$T$

$u$

Greek symbols

Heat capacity, $\mathrm{J} \mathrm{kg}^{-1} \mathrm{~K}^{-1}$

Mean cell size, $\mathrm{m}$

Activation energy, $\mathrm{J} \mathrm{mol}^{-1}$

Direction- integrated intensity, $\mathrm{W} \mathrm{m}^{-2}$

Enthalpy, $\mathrm{J} \mathrm{mol}^{-1}$

Volumetric heat transfer coefficient, $\mathrm{W} \mathrm{m}^{-3} \mathrm{~K}^{-1}$

Blackbody intensity of radiation, $\mathrm{W} \mathrm{m}^{-2} \mu \mathrm{m}^{-1} \mathrm{sr}^{-1}$

Intensity of radiation, $\mathrm{W} \mathrm{m}{ }^{-2} \mu \mathrm{m}^{-1} \mathrm{sr}^{-1}$

Flux diffusion, $\mathrm{kg} \mathrm{m}^{-2} \mathrm{~s}^{-1}$

Liter at normal conditions, $273 \mathrm{~K}$ and $1 \mathrm{~atm}$

Molecular weight, $\mathrm{kg} \mathrm{mol}^{-1}$

Mass flow of the gas, $\mathrm{kg} \mathrm{s}^{-1}$

Unit normal vector

Volumetric heat source, $\mathrm{W} \mathrm{m}^{-3}$

Reaction Rate, $\mathrm{mol} \mathrm{m}^{-3} \mathrm{~s}^{-1}$

Universal gas constant, $\mathrm{J} \mathrm{mol}^{-1} \mathrm{~K}^{-1}$

Reynolds number $(\mathrm{oud} / \mu)$

Unit vector into a given direction

Volumetric heat source term, $\mathrm{W} \mathrm{m}^{-3}$

Temperature, $\mathrm{K}$

Velocity, $\mathrm{m} \mathrm{s}^{-1}$
$\beta$
Extinction coefficient, $\mathrm{m}^{-1}$ 


$\begin{array}{ll}\varepsilon & \text { Emissivity } \\ \phi & \text { Porosity } \\ \Phi & \text { Incident solar flux density, } \mathrm{W} \mathrm{m}^{-2} \\ \eta & \text { Wavelength, } \mu \mathrm{m} \\ \kappa & \text { Absorption coefficient, } \mathrm{m}^{-1} \\ \lambda & \text { Thermal conductivity, } \mathrm{W} \mathrm{m}^{-1} \mathrm{~K}^{-1} \\ \mu & \text { Dynamic viscosity, } \mathrm{kg} \mathrm{m}^{-1} \mathrm{~s}^{-1} \\ \rho & \text { Density, } \mathrm{kg} \mathrm{m}^{-3} \\ \sigma & \text { Scattering coefficient, } \mathrm{m}^{-1} \\ \sigma_{b} & \text { Stefan-Boltzmann constant, } \mathrm{W} \mathrm{K}^{-4} \mathrm{~m}^{-2} \\ \tau & \text { Transmissivity of the window }\end{array}$

$\begin{array}{cl}\begin{array}{l}\text { Subscripts } \\ \text { chem }\end{array} & \text { Chemical } \\ \text { conv } & \text { Convective } \\ f & \text { Fluid } \\ \mathrm{H} & \text { Hydrolysis } \\ i & \text { Species } i \\ \mathrm{rad} & \text { Radiation } \\ \mathrm{R} & \text { Reduction } \\ s & \text { Solid } \\ w & \text { Wall }\end{array}$

\section{Introduction}

The conversion of concentrated solar energy into a sustainable energy carrier such as hydrogen is an attractive option to produce a long-term storable and transportable fuel without green house gas emissions. One of the most promising options to obtain "solar hydrogen" relies on the solar thermochemical cycles that present satisfactory energy efficiency due to the direct conversion of heat to hydrogen [1]. Several of these cycles were analyzed and demonstrated experimentally [2-5] and recently, special interest was paid in the use of the $\mathrm{Fe}_{3} \mathrm{O}_{4} / \mathrm{FeO}$ redox pair and mixed metal ferrites [6-12]. This iron-based process was first proposed by Nakamura [11] and it comprises two steps. The first one consists of a highly endothermic reduction reaction that needs temperatures above $1900 \mathrm{~K}$ to produce the $\mathrm{FeO}$ (wüstite phase) (thermal-reduction step). In the second step (hydrolysis step), hydrogen and $\mathrm{Fe}_{3} \mathrm{O}_{4}$ are obtained from the reaction of wüstite with water at about $800 \mathrm{~K}$ [11-12]. 
Mixed oxide materials such as ferrites (like nickel ferrites) were proposed to lower the temperature of the thermal reduction step below $1600 \mathrm{~K}$ while the reduced phase was still reactive with water to produce hydrogen at about $1200 \mathrm{~K}$ [9].

$$
\begin{array}{ll}
\mathrm{M}_{x} \mathrm{Fe}_{3-x} \mathrm{O}_{4} \rightarrow x \mathrm{MO}+(3-\mathrm{x}) \mathrm{FeO}+1 / 2 \mathrm{O}_{2} & \text { (Thermal-reduction Step) } \\
x \mathrm{MO}+(3-x) \mathrm{FeO}+\mathrm{H}_{2} \mathrm{O} \rightarrow \mathrm{M}_{x} \mathrm{Fe}_{3-x} \mathrm{O}_{4}+\mathrm{H}_{2} & \text { (Hydrolysis Step) }
\end{array}
$$

with $\mathrm{M}=\mathrm{Mn}, \mathrm{Co}, \mathrm{Ni}, \mathrm{Cu}, \mathrm{Zn} \ldots$

Due to the lower reduction temperature of the ferrites, a few solar reactor concepts have been developed and tested $[6,9,13]$. For example, a mixed iron oxide cycle was demonstrated in a $100 \mathrm{~kW}$ solar reactor operating below $1500 \mathrm{~K}$ [13]. The reactive material is coated on a multichannelled monolithic honeycomb. In a monolithic dual chamber solar reactor, a quasicontinuous $\mathrm{H}_{2}$ flow is produced by cyclic operation of the two reaction chambers through sequential oxidation and reduction steps at $1073 \mathrm{~K}$ and $1473 \mathrm{~K}$, respectively. A solar reactor that incorporates heat recuperation between the reduction and oxidation steps is being developed [14].

In order to implement this chemical process in the solar furnace of CNRS-PROMES laboratory, a volumetric solar receiver/reactor based on low cost ceramic structures is proposed. This reactor consists of a porous ceramic foam made of silicon carbide (Fig. 1) impregnated with the reactive material (e.g., $\mathrm{M}_{\mathrm{x}} \mathrm{Fe}_{3-\mathrm{x}} \mathrm{O}_{4}$ ) and deposited as a coated layer. This structure is directly irradiated by concentrated solar energy with the aim of obtaining the necessary reaction temperatures. With such a reactor configuration, several advantages can be expected, some of them are [15]: (I) the solid transport (reactants feeding and products collection) is avoided because of the use of a solid reactant fixed in the receiver; (II) the 
whole chemical process (hydrolysis and reduction reactions) can be achieved in the same reactor; (III) there is a high geometric surface area and therefore appropriate gas-solid interface contact, low pressure drop and high mass transfer performance because of using a porous media.

The modeling of reactors is a tool that permits the reactor design improvement. For example Villafán-Vidales et al. [16] developed a model of reactor for the $\mathrm{CeO}_{2}$ reduction in which the aperture radius and the particle concentration in the fluidized bed reactor were optimized to match the characteristics of the solar concentrator. For a gas phase reaction, the study made by Valdés-Parada et al. [17] is another example of optimization of the reactor size by means of this kind of technique. In the field of volumetric solar receivers or catalytic monoliths, the heat transfer to the reactor volume and the temperature homogenization are targeted [18-24]. However, the case of thermochemical systems and the influence of chemical reactions have been scarcely analyzed $[6,25]$. A mathematical model for the description of the cyclic watersplitting/regeneration process was formulated at the scale of a single channel (one dimensional problem) to describe a honeycomb monolithic reactor under the influx of solar radiation on its front face [6]. Other models focused on heat transfer simulation in catalytic monoliths [23-24]. Therefore, a two-dimensional model for a volumetric porous solar receiver/reactor devoted to the thermochemical hydrogen production is developed in this study. The solar radiation is not only considered as a boundary condition at the reactor front surface [6], but rather as a radiative heat source in the whole volume of the porous medium. The model is used to predict the temperature profile inside the receiver, since its direct determination by experimental measurements under high flux solar irradiation is awkward. It includes the mass, momentum and energy conservation equations as well as both the reduction and hydrolysis reactions. These heterogeneous surface reactions involve the redox coating on the pore channels of the volumetric receiver. The commercial software ANSYS 
FLUENT was used to solve the transport equations in the fluid phase. For the solid phase, the radiative transfer and kinetics of the chemical reactions were computed using the UDFs (User Defined Functions).

The aim of this study is to perform a parametric study and to predict the system performances as a function of operational conditions. A solar reactor prototype is proposed and tested to validate the model results.

\section{Solar reactor description}

The reactor consists of a horizontal cylindrical chamber $(0.035 \mathrm{~m}$ i.d. and $0.044 \mathrm{~m}$ long) that contains the porous ceramic structure (Fig. 2). The front of the device is directly irradiated by concentrated solar energy supplied by a solar furnace consisting of a sun-tracking heliostat and a $2 \mathrm{~m}$-diameter parabolic concentrator $\left(85 \mathrm{~cm}\right.$ focal distance, $120^{\circ}$ aperture, maximal power of $1.4 \mathrm{~kW}$ delivered at the focal point, Gaussian flux density distribution). The lateral walls of the foam are surrounded by an insulator and a hemispherical glass window separates the system from the ambient air to provide a controlled atmosphere inside the chamber. A flow of inert gas (nitrogen) enters by the front of the receiver, flows inside the porous foam and sweeps the gaseous product species out of the chamber.

\section{Mathematical model}

The model assumes that the flow within the monolith pore channels is laminar $(\operatorname{Re}<47$, the Reynolds number is based on the superficial gas velocity accounting for the void surface) and that the lateral walls are well insulated (adiabatic). The radiation entering the receiver is collimated with a Gaussian distribution, and the foam is considered as a gray, optically thick, 
absorbing, emitting and isotropic scattering media. The reaction rate expressions include all the possible mechanisms involved in the conversion of gas and solid species (e.g., adsorption, desorption, diffusion).

\subsection{Governing equations}

From the assumptions described above, the equations that were solved are:

(I) Mass conservation equation:

$$
\nabla \cdot(\rho u)=0
$$

(II) Momentum conservation equation:

$$
\nabla \cdot(\rho \vec{u} \vec{u})=\mu \Delta u-\nabla(p)+\vec{F}
$$

where $\vec{F}$ is the pressure drop in the ceramic foam. This term is calculated by using the UDFs and the following correlation is used [26]:

$$
\vec{F}=\frac{1039-1002 \phi}{d^{2}} \mu u+\frac{0.5138 \phi^{-5.739}}{d_{s}} \rho u^{2}
$$

In this equation, $\phi$ represents the material porosity and $d_{s}$ is the mean cell size and its value was taken from Wu et al. [26]. This correlation is valid for ceramic foams with porosity in the range of $0.66<\phi<0.93$, Reynolds number in the range of $10<\operatorname{Re}<400$ and a cross-section of the pore channel that approaches a circle [26].

(III) Energy equation for a porous media [27]:

For the fluid phase: 


$$
\nabla\left(\rho_{f} c_{p, f} u T_{f}\right)=\nabla \cdot\left(\lambda_{f} \nabla T_{f}-\Sigma H_{i} \vec{J}_{i}\right)+q_{f}^{\prime \prime}
$$

$q_{f}^{\prime \prime}$ denotes a heat source term that represents the convective heat exchange between the solid and the fluid ( $\left.S_{\text {conv }}\right)$, and the species diffusion term $\left(\Sigma H_{i} J_{i}\right)$ is added when chemical reactions are considered.

For the solid phase:

$$
\nabla\left(\rho_{s} c_{p, s} u T_{s}\right)=\nabla \cdot\left(\lambda_{\mathrm{eff}} \nabla T_{s}\right)+q_{s}^{\prime \prime}
$$

where $\lambda_{\text {eff }}$ is the thermal conductivity of the foam that is obtained by using the SchuetzGlicksman empirical formula [28]:

$$
\lambda_{\mathrm{eff}}=\frac{\lambda_{s}}{3}(1-\phi)
$$

$q_{s}^{\prime \prime}$ is a volumetric heat source term that includes the terms due to radiation $\left(S_{\text {rad }}\right)$, convective heat transfer between the solid and the fluid ( $\left.S_{\text {conv }}\right)$, and enthalpy of the chemical reaction $\left(S_{\text {chem }}\right)$ :

$$
q_{s}^{\prime \prime}=S_{\mathrm{chem}}+S_{\mathrm{conv}}+S_{\mathrm{rad}}
$$

\subsection{Fluid temperature modeling}

In the fluid phase energy equation (Eq. 4), the source term represents the convective heat transfer between the solid and the fluid:

$$
S_{\text {conv }}=h\left(T_{s}-T_{f}\right)
$$

The convective volumetric heat transfer coefficient $(h)$ is calculated by using the following empirical correlation that relates the porosity $\phi$ and the fluid velocity [29]:

$$
h=\frac{2.096 \phi^{0.38} \lambda_{f} \operatorname{Re}^{0.438} P(\phi)}{d_{s}^{2}}
$$


where $P(\phi)=-8.278 \phi^{0.38}+57,384 \phi^{1.38}-106.63 \phi^{2.38}+95.756 \phi^{3.38}-37.24 \phi^{4.38}$

This correlation is valid for porosity in the range of $0.66<\phi<0.93$ and Reynolds number in the range of $70<\operatorname{Re}<800[29]$.

Boundary conditions:

To obtain the temperature of the fluid phase, the applied boundary conditions are the following. The lateral wall is adiabatic. A mass flow inlet is imposed and the gas is supposed to be injected at $300 \mathrm{~K}$.

At the inlet $\left(\mathrm{x}=\mathrm{x}_{0}\right), \dot{m}_{g}=\dot{m}_{g, \text { set }}, T_{f, \text { inlet }}=300 \mathrm{~K}$

At the outlet $\left(\mathrm{x}=\mathrm{x}_{\mathrm{L}}\right)$, the pressure gradient is zero.

\subsection{Solid temperature modeling}

The source terms in the solid phase energy equation include the convective heat transfer between the solid and the fluid ( $\left.S_{\text {conv }}\right)$, the radiative term $\left(S_{\text {rad }}\right)$, and the chemical reaction term ( $\left.S_{\text {chem }}\right)$, see Eq. (7). The first one is obtained by using the equations 8 and 9 .

To compute the radiative term $\left(S_{\text {rad }}\right)$, it is necessary to solve the radiative transfer equation (RTE) [30]:

$$
\frac{d I_{\eta}(\mathbf{r}, \hat{\mathbf{s}})}{d s}=\kappa_{\eta} I_{b \eta}-\beta_{\eta} I_{\eta}+\frac{\sigma_{\eta}}{4 \pi} \int_{4 \pi} I_{\eta}\left(\hat{\mathbf{s}}_{i}\right) \Theta_{\eta}\left(\hat{\mathbf{s}}_{i} \hat{\mathbf{s}}\right) d \Omega_{i}
$$

In this equation, $I_{\eta}$ represents the intensity of radiation at point $\mathbf{r}$ in the medium that travels a distance $d s$ along the direction $\hat{\mathbf{s}}$. To solve equation (10), several approximated methods exist. The P1 approximation can be used to solve the RTE because the porous structure is considered as an optically thick and isotropic scattering media. 
P1 approximation is an analytical solution of the RTE that is based on the assumption that the media is optically thick and the radiation is scattered almost uniformly in every directions [30]. The assumption that radiation is perfectly diffuse at any point of the reactor may not be true in many cases, especially if the radiation entering the reactor is collimated. In this case a variation of the P1 approximation is used, generally known as a modified differential approximation. In this approximation, the intensity is treated as the sum of collimated and diffuse components, given the strong directionality of the solar source in this system. Mathematically, the modified differential approximation can be expressed as [31]:

$$
\nabla^{2} G_{d}-k_{d}^{2} G_{d}=q_{r}^{\prime \prime}
$$

with

$$
q_{r}^{\prime \prime}=\sigma \tau \Phi \exp (-\beta x)+4 \kappa \sigma_{b} T_{s}^{4}
$$

In this expression, $G_{d}$ is the diffuse integrated intensity over all the directions, $q_{r}^{\prime \prime}$ represents the source term that contains the emitted energy $\left(4 \kappa \sigma_{b} T_{s}^{4}\right)$ and the collimated component $(\tau \Phi \exp (-\beta x))$ that is attenuated exponentially. Then, the diffusion coefficient of the P1 approximation $\left(k_{d}\right)$ is:

$$
k_{d}=\sqrt{3 \kappa \beta}
$$

where $\beta=\kappa+\sigma$ is the extinction, $\kappa$ the absorption, and $\sigma$ the scattering coefficients.

The optical properties (absorption and scattering coefficients) of the foam are considered homogeneous and independent of the wavelength (gray media). The absorption and scattering coefficients depend on the porosity and are obtained from the following relations [32]:

$$
\begin{aligned}
& \kappa=\varepsilon\left(\frac{3}{2 d_{s}}\right)(1-\phi) \\
& \sigma=(2-\varepsilon)\left(\frac{3}{2 d_{s}}\right)(1-\phi)
\end{aligned}
$$


These coefficients can be estimated from the conditions of the geometric optics limit. The porous material is assumed as a monodisperse assembly of independently scattering voids (considered as particles) for large values of the size parameters [32].

To solve the diffuse incident radiation $G_{d}$, it is necessary to implement boundary conditions that can be used together with equation (11). In this problem, the Marshak boundary conditions were implemented [30]. The boundary conditions for the radiative flux are for the inlet and outlet boundaries:

$$
-\frac{G_{d}}{2}=\frac{1}{3 \beta} \overrightarrow{\mathbf{n}} \cdot \nabla G_{d}
$$

and for the wall, the emission and reflection are taken into account:

$$
\frac{\varepsilon_{w}}{2\left(2-\varepsilon_{w}\right)}\left(4 \sigma_{b} T_{w}^{4}-G_{d}\right)=\frac{1}{3 \beta} \overrightarrow{\mathbf{n}} \cdot \nabla G_{d}
$$

Once $G_{d}$ is found, the radiative source term is calculated by using:

$$
S_{r a d}=\kappa\left(4 \sigma_{b} T_{s}^{4}-G_{d}-\tau \Phi \exp (-\beta x)\right)
$$

\subsection{Chemical reactions modeling}

When implementing chemical reactions, the species transport equation balance is:

$$
\nabla\left(\rho \vec{u} Y_{i}\right)=\rho D_{i, m} \Delta Y_{i}+M_{i} R_{\text {chem } i}
$$

where $Y_{i}$ is the local mass fraction of the species $i, D_{i, m}$ is the mass diffusion coefficient for the species $i, \mathrm{M}_{\mathrm{i}}$ is the molecular weight, and $R_{\mathrm{chem} i}$ is the chemical source term, which relates to the net rate of production of species $i$ by chemical reaction.

In this work the reduction and hydrolysis reactions were modeled separately. The aim of these simulations is to evaluate the impact of the reactions on the temperature distribution. The 
information related to chemical reactions data (order of reaction and kinetic parameters) was taken from Agrafiotis et al. [6].

\subsubsection{Thermal-reduction step}

The thermal reduction reaction is highly endothermic and needs temperatures above $1400 \mathrm{~K}$

[6]. The heat source term related to the chemical reaction (Eq. 7) is expressed as:

$$
S_{\text {chem }}=R_{\text {red }} \Delta H_{\text {red }}
$$

where $\Delta H_{\text {red }}$ is the enthalpy of the reduction reaction and its value was obtained in the case of $\mathrm{NiFe}_{2} \mathrm{O}_{4}$ by using the HSC chemistry 5.11 software [33]; $R_{\mathrm{red}}$ is the net reaction rate with Arrhenius-type temperature dependence:

$$
R_{\mathrm{red}}=k_{0, \mathrm{R}} \exp \left(\frac{-E_{\mathrm{a}, \mathrm{R}}}{R_{g} T_{s}}\right)
$$

where $k_{0, \mathrm{R}}$ is the pre-exponential factor and $E_{\mathrm{a}, \mathrm{R}}$ is the activation energy [6].

\subsubsection{Hydrolysis step}

The hydrolysis reaction is an exothermic step that is carried out at temperatures around $1200 \mathrm{~K}$. In this case, the volumetric heat source term of Eq. 7 is expressed as:

$$
S_{\text {chem }}=R_{\text {hy d }} \Delta H_{\text {hyd }}
$$

with $R_{\text {hyd }}=k_{0, \mathrm{H}} \exp \left(\frac{-E_{\mathrm{a}, \mathrm{H}}}{R_{g} T_{s}}\right)\left[\mathrm{H}_{2} \mathrm{O}\right]$

The value of the enthalpy of the hydrolysis reaction is calculated by using HSC chemistry [33]. 
The data used for the evaluation of the system are shown in table 1 . The considered compound involved in the two-step cycle is $\mathrm{NiFe}_{2} \mathrm{O}_{4}$. The properties of the monolith materials correspond to those of silicon carbide, and the influence of the coating on the physical properties is neglected.

\subsection{Methodology}

The solar receiver was simulated with ANSYS Computational Fluid Dynamics (ANSYS CFD) and User-Defined Functions (UDFs). The UDFs are programmed functions that are coupled with the ANSYS-FLUENT solver for enhancing the standard features of the code. These UDFs are usually used to define boundary conditions, material properties and source terms. The developed model solves the 2D steady state continuity, momentum and energy equations for an axi-symmetrical flow (see Fig.2). The SIMPLE algorithm for the pressurevelocity coupling was used. The P1 approximation and momentum equations were discretized by applying the second-order upwind advection model and the energy equation by employing the third-order accurate scheme QUICK.

Simulations were first conducted for a non-reactive flow in order to determine the thermal behavior of the reactor for different operational conditions; then chemical reactions were included into the model for studying their impact on the temperature distribution. The model convergence criterion for the residuals was set to $1 \times 10^{-10}$.

In the non-reactive flow simulations, the inert gas $\left(\mathrm{N}_{2}\right)$ is assumed to enter the cavity at $300 \mathrm{~K}$ and 1 atm. The nitrogen was injected by the front of the reactor and several gas flow rates were considered: $0.01,1,6,10$, and $20 \mathrm{~L}_{\mathrm{n}} / \mathrm{min}$ (given at normal conditions, $273 \mathrm{~K}$ and $1 \mathrm{~atm}$ ). 
The front of the silicon carbide foam is subjected to concentrated solar radiation (total incident power of $1 \mathrm{~kW}$, mean concentration of 1040 suns, 1 sun $=1 \mathrm{~kW} / \mathrm{m}^{2}$ ), which can be represented either by a constant mean solar flux density (uniform on the foam surface) or by a Gaussian distribution to better match the characteristics of the solar concentrating system:

$$
\Phi=A \exp \left(-B r^{2}\right)
$$

where $A=1.5 \times 10^{6} \mathrm{~W} / \mathrm{m}^{2}$ and $B=2560 \mathrm{~m}^{-2}$. These values were obtained experimentally and correspond to the characteristics of typical parabolic solar concentrators.

In the next simulations, a reactive flow was modeled in order to study the effect of the chemical reaction on the temperature distribution in the gas and solid phases. Both the reduction and hydrolysis reactions were analyzed separately. In the reduction step, nitrogen was supposed to enter within the receiver at a flow rate of $6 \mathrm{~L}_{\mathrm{n}} / \mathrm{min}$ and an incident solar irradiation characterized by a Gaussian flux distribution was considered. An inlet gas mixture composed of nitrogen and water $\left(1.2 \mathrm{~L}_{\mathrm{n}} / \mathrm{min}\right.$ of $\mathrm{H}_{2} \mathrm{O}$ and $8 \mathrm{~L}_{\mathrm{n}} / \mathrm{min}$ of $\left.\mathrm{N}_{2}\right)$ was considered in the hydrolysis step.

\section{Results and discussion}

\subsection{Non-reactive flow simulations}

The solid and fluid temperature distributions are depicted in Fig. 3 (for a foam porosity of 0.9 and a $\mathrm{N}_{2}$ flow rate of $6 \mathrm{~L}_{\mathrm{n}} / \mathrm{min}$ ). The fluid starts to heat up until reaching a temperature of $1690 \mathrm{~K}$; then the temperature decreases until 1300K (Fig. 3A). The solid reaches the highest temperature $(1700 \mathrm{~K})$ at the front vicinity (about $1 \mathrm{~cm}$ from the front surface) due to the 
impinged direct irradiation and then, the temperature starts to decrease because of heat exchange with the fluid (Fig. 3B).

The temperature of the porous media along the symmetry axis is represented in Fig. 4. The gas flow rate has a strong impact on the temperature of the material. The higher the gas flow rate, the lower the temperature. The temperature tends to increase in the first few centimeters of the reactor and then it decreases toward the outlet. The maximum temperature of the foam is generally observed at a position between 0.5 and $1.5 \mathrm{~cm}$ from the front surface (except for the lowest gas flow rate). A flow rate lower than $20 \mathrm{~L}_{\mathrm{n}} /$ min permits to reach temperatures above $1400 \mathrm{~K}$ in the major part of the reactor. Such temperatures are suitable to carry out the thermal-reduction step, which suggests that the reaction can occur in the whole material. It may be possible to obtain the required reduction temperatures with a flow rate of $20 \mathrm{~L}_{\mathrm{n}} / \mathrm{min}$, but only in a small part of the material (between 1 and $2 \mathrm{~cm}$ from the front face). Otherwise, the material may be destroyed by using gas flow rates lower than $1 \mathrm{~L}_{\mathrm{n}} / \mathrm{min}$, because the maximal temperatures are above the melting temperature of the foam (1773K).

The temperature distributions in the solid and the fluid for a foam porosity of 0.7 and an incident Gaussian solar flux density distribution are presented in Fig. 5. The distributions are quite different from the previous case with a different porosity (Fig. 3). Indeed, the maximum temperatures are located at the front surface of the foam, then the temperatures are constant along the $y$-axis and change linearly along the symmetry $\mathrm{x}$-axis.

The temperature of the material along the symmetry axis for the same incident solar flux density distribution is shown in Fig. 6. In this case, the temperature decreases almost linearly along the receiver and, similarly to the previous case (Fig. 4), the flow rates lower than 20 $\mathrm{L}_{\mathrm{n}} / \mathrm{min}$ are necessary to reach the temperatures required in the endothermic thermal reduction reaction (over 1400K). In addition, the maximal temperature (1834K) is observed for the lowest gas flow rate, but it is higher than the maximal temperature that can withstand the 
receiver material. The gas flow rate must be above $1 \mathrm{~L}_{\mathrm{n}} /$ min to keep the temperature below the melting point of the foam.

The model was then applied to investigate the effect of the foam length on the temperature distribution. Three different lengths of the receiver were analyzed in figures 7 and $8: \mathrm{x}_{\mathrm{L} 1}=2.2$ $\mathrm{cm}, \mathrm{x}_{\mathrm{L} 2}=4.4 \mathrm{~cm}$, and $\mathrm{x}_{\mathrm{L} 3}=6.6 \mathrm{~cm}$. The diameter of the foam was kept unchanged $(3.5 \mathrm{~cm})$. The results show that the shorter the receiver length, the lower the solid and fluid temperatures in the first $60 \%$ of the foam length. At the end of the foam (last 40\%), the inverse tendency is obtained: both the solid and fluid temperatures decrease when increasing the receiver length. The temperature decrease along the $\mathrm{x}$-axis is due to the heat transfer and temperature compensation between the solid and the gas. Anyway, the temperature difference along the receiver $\mathrm{x}$-axis is not very large $(50-80 \mathrm{~K})$ and so, the receiver length does not affect significantly the temperature distribution.

Another parametric study was related to the porosity of the material that was already shown to modify the temperature distribution of the solid (Figs. 3 and 5). In the simulations, several mean porosities of the foam $(0.66,0.7,0.8$, and 0.9$)$ were considered with the aim of analyzing their impact on the solid and fluid temperatures. The results of these simulations are shown in figures 9 and 10 for an incident Gaussian solar flux distribution and an inlet gas flow rate of $6 \mathrm{~L}_{\mathrm{n}} / \mathrm{min}$. For the foam temperature profile (Fig. 9), the porosity impacts slightly the temperature of the solid. The maximal solid temperature is around $1710 \mathrm{~K}$, which corresponds to a porosity of 0.8 . This temperature maximum is displaced along the symmetry axis when increasing the porosity. The temperature displacement along the axis is a "volumetric effect" that tends to decrease the radiative losses at the inlet, which leads to an increase of the solid and fluid temperatures at the outlet. Anyway in all the cases, the maximal temperature is almost the same (around $1700 \mathrm{~K}$ ) and the minimal one is $1300 \mathrm{~K}$ at the outlet of the foam. Figure 10 presents the dependence of the fluid temperature on the porosity, which 
shows that the temperature remains almost unchanged whatever the different porosities considered.

The influence of the foam mean cell size on the temperature distribution was analyzed. Four representative mean cell sizes $(0.155,0.2,0.336$, and $0.449 \mathrm{~cm})$ were considered and the values were taken from $\mathrm{Wu}$ et al. [26]. The impact of the mean cell size on the foam temperature profile is not significant (Fig. 11). At the inlet of the foam (first $0.5 \mathrm{~cm}$ ), the temperature increases slightly (up to $1720 \mathrm{~K}$ ) when the cell size decreases but, in the remaining part of the foam, the temperature remains almost constant regardless of the cell size (temperature difference of 10-20K). As the cell size increases, the radiation losses at the inlet decrease and the outlet temperatures are higher. It is possible to reach the reduction temperature $(1400 \mathrm{~K})$ in the major part of the foam whatever the cell size.

\subsection{Reactive flow simulations}

\section{I) Reduction Step}

The solid and fluid temperature distributions along the $\mathrm{x}$-axis with and without the reduction reaction are compared in figure 12 . As expected, both temperatures decrease when accounting for the endothermic reduction reaction. In addition, the temperatures of the fluid and the solid tend to homogenize after about $1 \mathrm{~cm}$ from the inlet of the foam. However, the impact of the reduction reaction on the temperatures is weak (maximum temperature difference below $50 \mathrm{~K}$ ) although the reaction is highly endothermic. This is due to the fact that the energy required by the chemical reaction is lower than the energy losses by radiation and convection. The thermochemical reactor efficiency, defined as the enthalpy change of the reduction reaction divided by the thermal power input, is less than $1 \%$. This means that the chemical reaction 
only consumes a low fraction of the energy entering the reactor. An energy-balance reveals that about $18 \%$ of the energy loss resulted from heat convection and $81 \%$ resulted from reradiation from the foam (assuming adiabatic walls without conduction losses). The radiation losses can be minimized by settling the foam within a cavity with an aperture and by augmenting the solar flux density such that the aperture size can be reduced. The thermochemical efficiency can also be improved by increasing the amount of reactive material coated on the foam.

\section{II) Hydrolysis Step}

The required reaction temperature in the hydrolysis step is lower than the temperature of the reduction reaction to avoid competition between reactions. Nevertheless it is necessary to reach temperatures around $1200 \mathrm{~K}$. Otherwise, the hydrolysis reaction is not favored because of kinetic limitations if the temperature is too low or thermodynamic limitations if the temperature is too high (reduction reaction favored). In order to adjust the temperature of the receiver, the influence of the incident solar power on the temperature of the solid is studied (Fig. 13). As a result, the optimal solar power to conduct the hydrolysis step at the desired temperature of $1200 \mathrm{~K}$ is at least $500 \mathrm{~W}$ and it must not exceed $700 \mathrm{~W}$.

\section{Experimental validation}

A validation of the reactor model was performed thanks to an experimental campaign without chemical reaction. The measured experimental data were related to the inlet and outlet temperatures of the foam. The laboratory-scale solar reactor was settled at the focus of a $2 \mathrm{~m}$ diameter parabolic solar concentrator. The reactor configuration was similar to the simulated 
system (Fig. 2). The temperature measurements were carried out for gas flow rates of 1, 2, 4, and $6 \mathrm{~L}_{\mathrm{n}} / \mathrm{min}$. The inlet temperature (measured on the front face at the center of the irradiated foam) was obtained by employing a "solar-blind" pyrometer (bandwidth of the filter: 4.9- 5.5 $\mu \mathrm{m})$ fixed at the center of the parabolic mirror. The outlet temperature (measured at the center of the rear part of the foam) was measured by an optical pyrometer (wavelength of $5.12 \mu \mathrm{m}$ ) located at the backside of the reactor. The measurements were made through fluorine windows $\left(\mathrm{CaF}_{2}\right)$ located at the front and at the back of the reactor.

During experiments, the reactor was heated by the solar furnace in a flow of inert gas (2 $\mathrm{L}_{\mathrm{n}} / \mathrm{min}$ ). The duration to reach the steady-state temperature at the front face (foam inlet) was about 20 min, whereas steady state condition was not definitely achieved at the foam outlet. At steady state (front face temperature), the nitrogen flow rate was changed sequentially to 4 , 6, and $1 \mathrm{~L}_{\mathrm{n}} / \mathrm{min}$ after a stabilization period between each change. The maximal temperature reached at the inlet of the foam was $1720 \mathrm{~K}$ for a $\mathrm{N}_{2}$ flow rate of $2 \mathrm{~L}_{\mathrm{n}} / \mathrm{min}$.

Figure 14 shows the simulation results (steady state temperatures) along with the measured temperatures of the foam for one typical experiment (with a stable direct normal irradiation of $957 \mathrm{~W} / \mathrm{m}^{2}$ ). According to the simulation predictions, the gas flow rate has a significant impact on the temperature of the foam, especially at the inlet (Figs. 4 and 6). The temperature measured experimentally at the inlet of the receiver (front face) tends to decrease when increasing the $\mathrm{N}_{2}$ flow rate because of the enhanced heat transfer between the gas and the solid. Inversely, the temperature at the outlet is not modified significantly when increasing the gas flow rate. The influence of the gas flow rate on the temperature of the foam is thus in agreement with the model predictions.

The heating phase shows that steady state temperature is not reached completely, in particular at the back surface. This temperature continues to rise slightly during the experiment for a given gas flow rate. This is because the thermal equilibrium in the reactor is not reached. In 
contrast, the temperatures given by simulation are calculated at steady state conditions. The matching between the simulated and the measured temperatures at the inlet is fairly good (temperature difference below $100 \mathrm{~K}$ ). However, the simulations predict lower temperatures than the measured ones at the outlet of the foam. Anyway, the temperature difference is below 200K. The temperatures discrepancies are mainly due to the model assumptions: a perfectly insulated receiver is considered in the model resulting in a higher inlet temperature and radiation heat losses are over-estimated at the outlet resulting in a lower temperature.

\section{Conclusions}

A 2D - computational fluid dynamic model was developed to predict the reactor performances at different operational conditions. Simulations were first carried out for a non-reactive flow and then chemical reactions were implemented.

For a non-reactive flow, the influence of different inert gas flow rates for a Gaussian incident solar flux distribution (mean incident solar flux density of $1040 \mathrm{~kW} / \mathrm{m}^{2}$ ) was analyzed. The results showed that gas flow rates lower than $20 \mathrm{~L}_{\mathrm{n}} /$ min were necessary to reach high enough temperatures required by the thermal-reduction reaction, namely above $1400 \mathrm{~K}$. A minimum inert gas flow rate (above $1 \mathrm{~L}_{\mathrm{n}} / \mathrm{min}$ ) was however required to avoid exceeding the maximum temperature allowed by the receiver material, which may cause irreversible damage. Another parametric study was related to the porosity of the ceramic receiver that affects mainly the temperature distribution in the solid near the front surface of the porous medium. Numerical simulations revealed that the receiver length does not affect significantly the temperature distribution of both the solid and the fluid phase. Likewise, changing the mean cell size leads to negligible change in the foam and fluid temperature distributions. 
Regarding simulations accounting for a reactive flow, the impact of the endothermic reduction reaction on the temperature distributions was first analyzed, and a temperature decrease reaching about $50 \mathrm{~K}$ was evidenced due to the endothermic reaction.

In the case of the hydrolysis reaction producing hydrogen, a parametric study regarding the incident solar power was performed to adjust the reaction temperature. As a result, a range of incident solar power of 500-700 $\mathrm{W}$ is necessary to reach reaction temperatures of about $1200 \mathrm{~K}$ in the porous foam receiver. The solid temperature increases when the solar power is above $700 \mathrm{~W}$, which favors the reduction reaction.

A validation of the model with experimental data was realized. The matching of simulated and measured temperatures at the inlet of the foam is fairly satisfactory. The simulation and the sensitivity analysis of this kind of reactor permit to identify the suitable operating conditions of the designed reactor and the construction parameters in order to obtain the desired performances. On the basis of these numerical simulations, the solar reactor designed to carry out the two chemical steps of the process in a semi-continuous mode will be developed for the production of hydrogen.

\section{Acknowledgement}

H.I Villafán-Vidales would like to gratefully acknowledge CONACYT (México) for financial support. The authors also thank ANR (contract ANR-09-JCJC-0004-01) for funding this study and R. Garcia from technical staff of PROMES for solar reactor design. 


\section{References}

[1] N.Z Muradov, T.N. Veziroğlu, "Green" path from fossil-based to hydrogen economy: An overview of carbon-neutral technologies. Int. J. Hydrogen Energy 33 (2008) 6804-6839.

[2] A. Steinfeld, P. Kuhn, A. Reller, R. Palumbo, J. Murray, Y. Tamaura, Solar-processed metals as clean energy carriers and water-splitters, Int. J. Hydrogen Energy 23-9 (1998) 767774.

[3] S. Abanades, G. Flamant, Thermochemical hydrogen production from a two-step solardriven water-splitting cycle based on cerium oxides, Solar Energy 80 (2006) 1611-1623.

[4] S. Abanades, P. Charvin, P. Lemort, G. Flamant, Novel two-step $\mathrm{SnO}_{2} / \mathrm{SnO}$ water splitting cycle for solar thermochemical production of hydrogen, Int. J. Hydrogen Energy 33 (2008) 6021-6030.

[5] P. Charvin, S. Abanades, F. Lemort, G. Flamant, Analysis of solar chemical processes for hydrogen production from water splitting thermochemical cycles, Energy Conversion and Management 49 (2008) 1547-1556.

[6] C. Agrafiotis, C. Pagkoura, S. Lorentzu, M. Kostoglou, A.G. Konstandopoulos, Hydrogen production in solar reactors, Catalysis Today 127 (2007) 265-277. 
[7] P. Charvin, S. Abanades, F. Lemort, G. Flamant, Hydrogen production by three-step solar thermochemical cycles using hydroxides and metal oxide systems, Energy and Fuels 21 (2007) 2919-2928.

[8] N. Gokon, S. Takahashi, H. Yamamoto, T. Kodama, Thermochemical two-step watersplitting reactor with internally circulating fluidized bed for thermal reduction of ferrite particles, Int. J. Hydrogen Energy 33 (2008) 2189-2199.

[9] N. Gokon, H. Murayama, A. Nagasaki, T. Kodama, Thermochemical two-step water splitting cycles by monoclinic $\mathrm{ZrO}_{2}$-supported $\mathrm{NiFe}_{2} \mathrm{O}_{4}$ and $\mathrm{Fe}_{3} \mathrm{O}_{4}$ powders and ceramic foam devices, Solar Energy 83 (2009) 527-537.

[10] M. Roeb, J.P. Säck, P. Rietbrock, C. Prahl, H. Schreiber, M. Neises, et al. Test operation of a $100 \mathrm{~kW}$ pilot plant for solar hydrogen production from water on a solar tower, Solar Energy (2010), doi:10.1016/j.solener.2010.04.014.

[11] T. Nakamura, Hydrogen production from water utilizing solar heat at high temperatures, Solar Energy 19 (1977) 467-475.

[12] P. Charvin, S. Abanades, F. Lemort, G. Flamant, Two-step water splitting thermochemical cycle based on iron oxide redox pair for solar hydrogen production, Energy 32 (2007) 1124-1133. 
[13] M. Roeb, M. Neises, J.P. Säck, P. Rietbrock, N. Monnerie, J. Dersch, M. Schmitz, C.

Sattler. Operational strategy of a two-step thermochemical process for solar hydrogen production. Int. J. Hydrogen Energy 34 (2009) 4537-4545.

[14] J.E. Miller, M.D. Allendorf, R.B. Diver, L.R. Evans, N.P. Siegel, J.N. Stuecker, Metal oxide composites and structures for ultra-high temperature solar thermochemical cycles, J. Mater. Sci. 43 (2008) 4714-4728.

[15] C. Agrafiotis, M. Roeb, A.G. Konstandopoulos, L. Nalbandian, V.T. Zaspalis, C. Sattler, P. Stobbe, A.M. Steele, Solar water splitting for hydrogen production with monolithic reactors. Solar Energy 79 (2005) 409-421.

[16] H.I. Villafán-Vidales, C.A. Arancibia-Bulnes, U. Dehesa-Carrasco, H. Romero-Paredes, Monte Carlo radiative transfer simulation of a cavity solar reactor for the reduction of cerium oxide, Int. J. Hydrogen Energy 34 (2009) 115-124.

[17] F.J. Valdés- Parada, H. Romero-Paredes, G. Espinosa-Paredes, Numerical simulation of a tubular solar reactor for methane cracking, Int. J. Hydrogen Energy (2011), doi:10.1016/j.ijhydene.2010.12.022.

[18] V. Tomašic, F. Jović, State-of-the-art in the monolithic catalysts/reactors, Applied Catalysis A: General 311 (2006) 112-221. 
[19] M. Becker, Th. Fend, B. Hoffschmidt, R. Pitz-Paal, O. Reutter,V. Stamatov, M. Steven,

D. Trimis, Theoretical and numerical investigation of flow stability in porous materials applied as volumetric solar receivers, Solar Energy 80 (2006)1241-1248.

[20] Th. Fend, High porosity materials as volumetric receivers for solar energetics, Optica Applicata 40-2 (2010) 271-284.

[21] Th. Fend, B. Hoffschmidt, R. Pitz-Paal, O. Reutter, P. Rietbrock, Porous materials as open volumetric solar receivers: Experimental determination of thermophysical and heat transfer properties, Energy 29 (2004) 823-833.

[22] A. Kribus, H. Ries, W. Spirkl, Inherent limitations of volumetric solar receivers, Journal of Solar Energy Engineering 118-3 (1996) 151-155.

[23] D.J. Worth, A. Spence, P.I. Crumpton, S.T. Kolaczkowski, Radiative exchange between square parallel channels in a concentric monolith structure, Int. J. Heat and Mass Transfer 39(7) (1996) 1463-1474.

[24] S.T. Kolaczkowski, P. Crumpton, A. Spence, Modelling of heat transfer in non-adiabatic monolithic reactors, Chem. Eng. Sci. 43(2) (1988) 227-231.

[25] J. Dersh, A. Mathijssen, M. Roeb, M. Sattler M, Modelling of a solar thermal reactor for hydrogen generation, $5^{\text {th }}$ International Modelica Conference, 2006. 
[26] Z. Wu, C. Caliot, F. Bai, G. Flamant, Z. Wang, J. Zhang, C. Tian, Experimental and numerical studies of the pressure drop in ceramic foams for volumetric solar receiver applications, Applied Energy 87 (2010) 504-513.

[27] A. Bejan, D. Nield, Convection in Porous media, Third Ed., Springer, New York, 2006.

[28] M.A Schuetz, L.R. Glicksman, A basic study of heat transfer through foam insulation, Journal of Cellular Plastics 20-2 (1984) 114-121.

[29] Z. Wu, C. Caliot, F. Bai, G. Flamant, Z. Wang, Numerical simulation of convective heat transfer between air flow and ceramic foams to optimize volumetric solar air receiver performances, Int. J. Heat and Mass Transfer 54 (2011) 1527-1537.

[30] M. Modest, Radiative heat transfer, Second ed., Academic Press, San Diego, 2003.

[31] A. Ishimaru, Wave Propagation and Scattering in Random Media, Oxford University press, Oxford, 1997.

[32] K. Vafai, Handbook of Porous Media, Second Ed., Taylor and Francis, 2005.

[33] HSC Chemistry 5.1. Outokumpu Research Oy, Pori, Finland, 2002. 


\section{Figure captions}

Fig.1. Silicon carbide (SiC) foam

Fig. 2: Cross-section sketch of the solar reactor

Fig 3. Temperature distributions in the fluid (A) and in the foam (B) for an incident Gaussian solar flux distribution, a porosity of 0.9 , and a gas flow rate of $6 \mathrm{~L}_{\mathrm{n}} / \mathrm{min}$

Fig 4. Temperature profile of the porous reactor along the symmetry axis for several inert gas flow rates (porosity of 0.9 , incident solar radiation with a Gaussian distribution)

Fig. 5. Temperature distributions in the fluid (C) and in the foam (D) for an incident Gaussian solar flux distribution, a porosity of 0.7 , and a gas flow rate of $6 \mathrm{~L}_{\mathrm{n}} / \mathrm{min}$

Fig 6. Temperature of the foam along the symmetry axis for several inert gas flow rates (porosity of 0.7 , incident solar radiation with a Gaussian distribution)

Fig 7. Temperature of the foam as a function of the dimensionless foam length $\left(x / x_{L}\right)$ for several reactor lengths (incident Gaussian flux distribution and inlet gas flow rate of $6 \mathrm{~L}_{\mathrm{n}} / \mathrm{min}$ )

Fig 8. Temperature of the fluid as a function of the dimensionless foam length $\left(\mathrm{x} / \mathrm{x}_{\mathrm{L}}\right)$ for several reactor lengths (incident Gaussian flux distribution and inlet gas flow rate of $6 \mathrm{~L}_{\mathrm{n}} / \mathrm{min}$ ) 
Fig 9. Temperature of the foam along the $\mathrm{x}$-axis for several porosities (inlet gas flow rate of 6 $\left.\mathrm{L}_{\mathrm{n}} / \mathrm{min}\right)$

Fig 10. Temperature of the fluid along the x-axis for several porosities (inlet gas flow rate of 6 $\left.\mathrm{L}_{\mathrm{n}} / \mathrm{min}\right)$

Fig 11. Temperature of the foam along the x-axis for different foam mean cell sizes (inlet gas flow rate of $6 \mathrm{~L}_{\mathrm{n}} / \mathrm{min}$ )

Fig. 12. Fluid (FT) and solid (ST) temperature distributions with and without the reduction reaction $(\mathrm{RR})$

Fig. 13. Temperature of the solid along the $\mathrm{x}$-axis for several incident solar powers

Fig. 14. Experimental and calculated temperatures of the foam at the inlet and at the outlet for $\mathrm{N}_{2}$ flow rates of $1,2,4$, and $6 \mathrm{~L}_{\mathrm{n}} / \mathrm{min}$ and a direct normal irradiation of $957 \mathrm{~W} \cdot \mathrm{m}^{-2}$. Temperatures given by simulation are calculated at steady state conditions. 
Table 1. Data used in the simulations

\begin{tabular}{ll}
\hline$\phi$ & $0.66-0.7-0.8-0.9$ \\
\hline$d_{s}(\mathrm{~m})$ & 0.002 \\
\hline$\varepsilon$ (foam emissivity) & 0.92 \\
\hline$\varepsilon_{w}($ wall emissivity $)$ & 0.3 \\
\hline$\lambda_{s}\left(\mathrm{~W} \mathrm{~m}^{-1} \mathrm{~K}^{-1}\right)$ & 80 \\
\hline$C_{p, s}\left(\mathrm{~J} \mathrm{~kg}^{-1} \mathrm{~K}^{-1}\right)$ & 750 \\
\hline$\rho_{s}\left(\mathrm{~kg} \mathrm{~m}^{-3}\right)$ & 3200 \\
\hline$\Delta H_{\mathrm{R}}\left(\mathrm{J} \mathrm{mol}^{-1}\right)$ & 319000 \\
\hline$\Delta H_{\mathrm{H}}\left(\mathrm{J} \mathrm{mol}^{-1}\right)$ & 286000 \\
\hline$E_{a, \mathrm{R}}\left(\mathrm{J} \mathrm{mol}^{-1}\right)$ & 240000 \\
\hline$E_{a, \mathrm{H}}\left(\mathrm{J} \mathrm{mol}^{-1}\right)$ & $10^{5}$ \\
\hline$k_{0, \mathrm{R}}\left(\mathrm{mol} \mathrm{m}^{-3} \mathrm{~s}^{-1}\right)$ & $10^{6}$ \\
\hline$k_{0, \mathrm{H}}\left(\mathrm{s}^{-1}\right)$ & 35 \\
\hline
\end{tabular}




\section{Figure}

Click here to download high resolution image ACCEPTED MANUSCRIPT
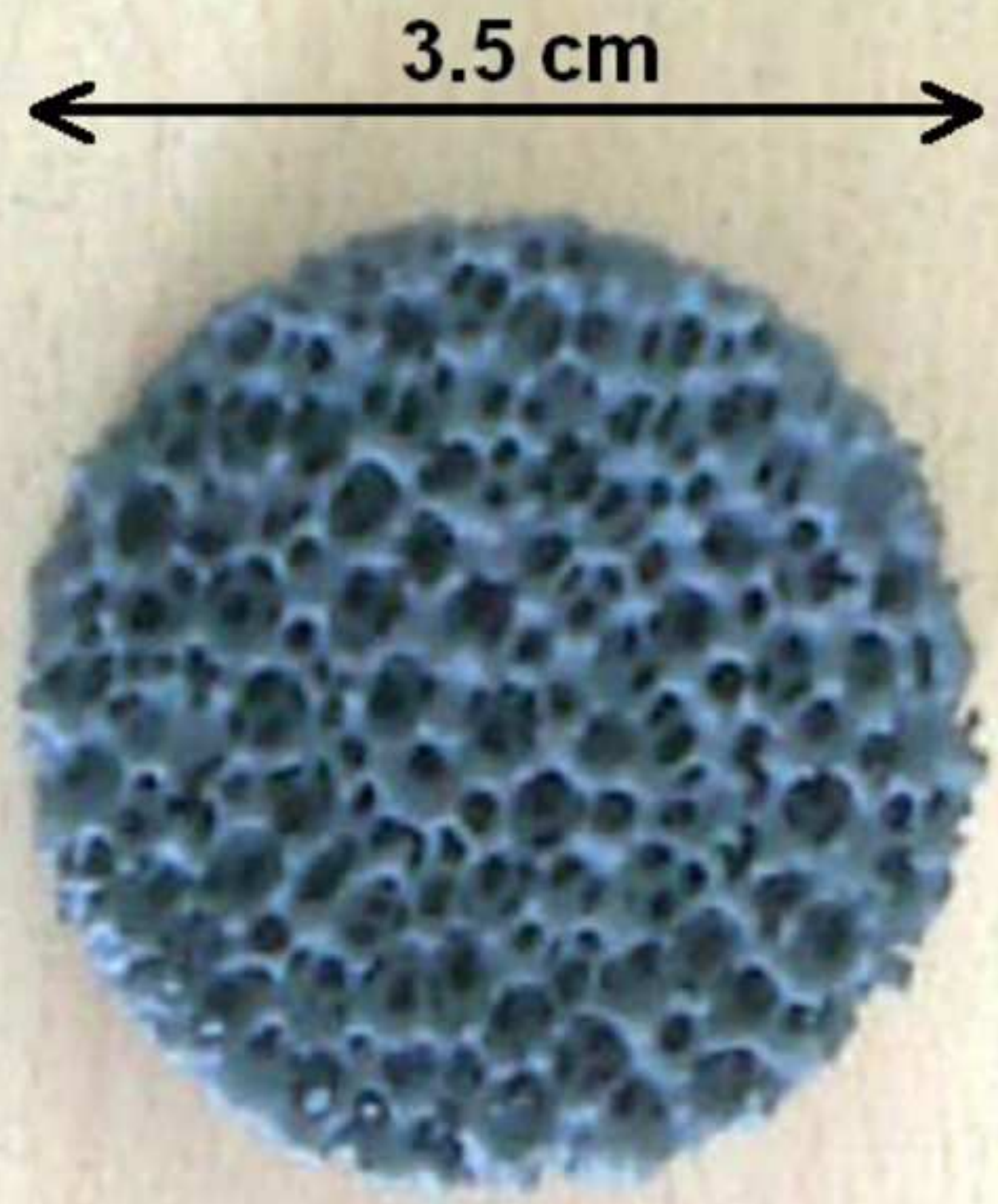


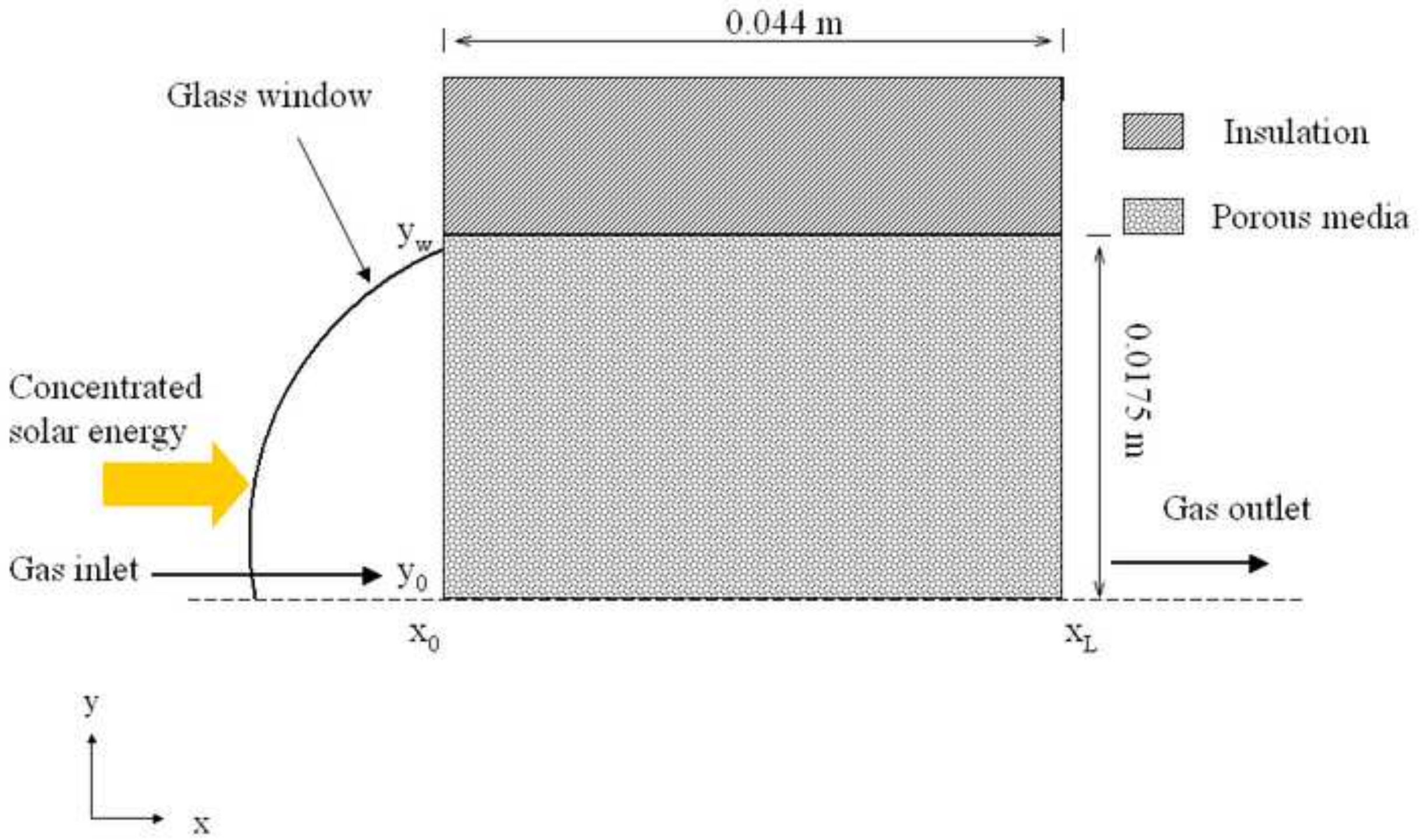




\section{T (K)}

A

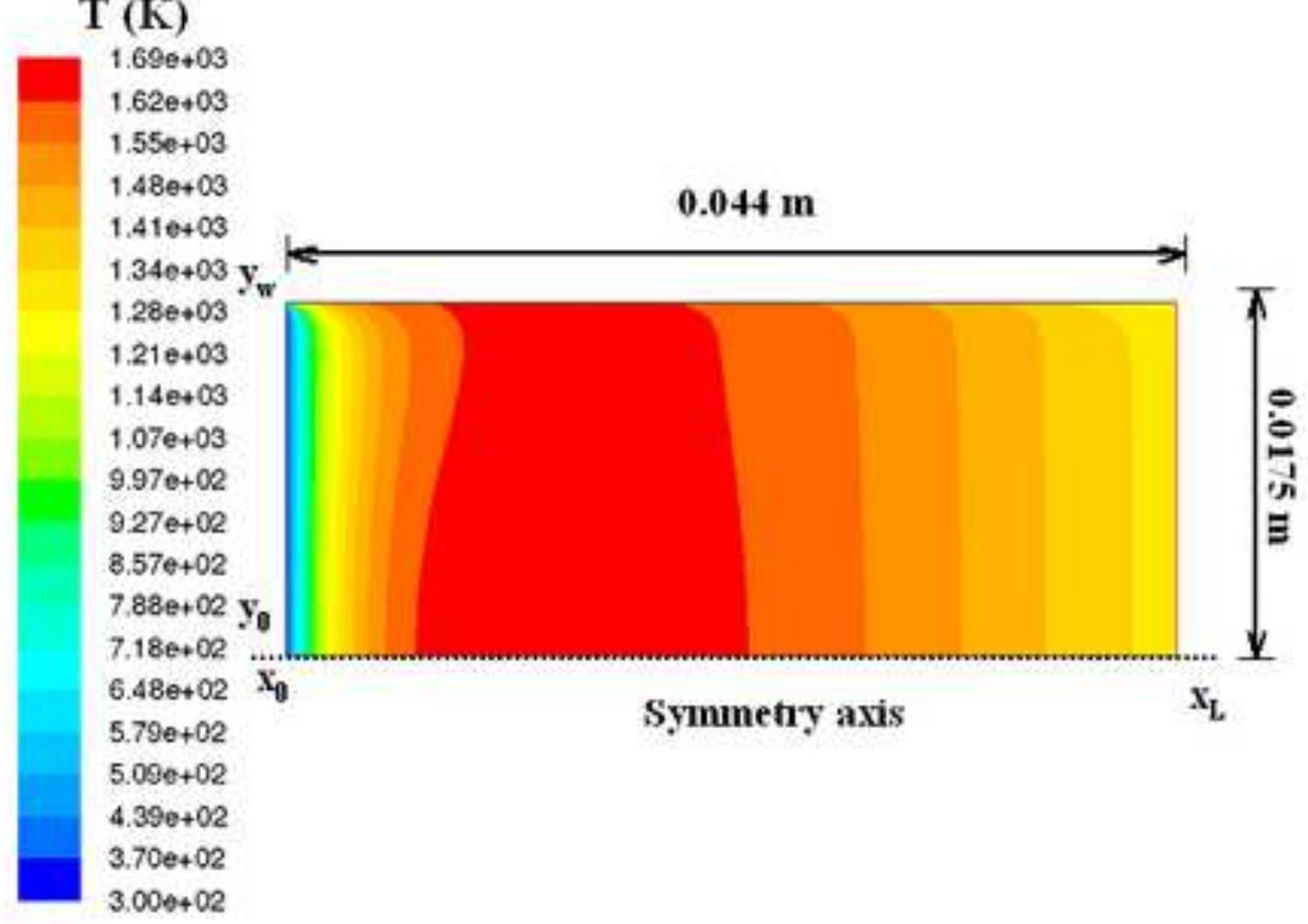

T (K)

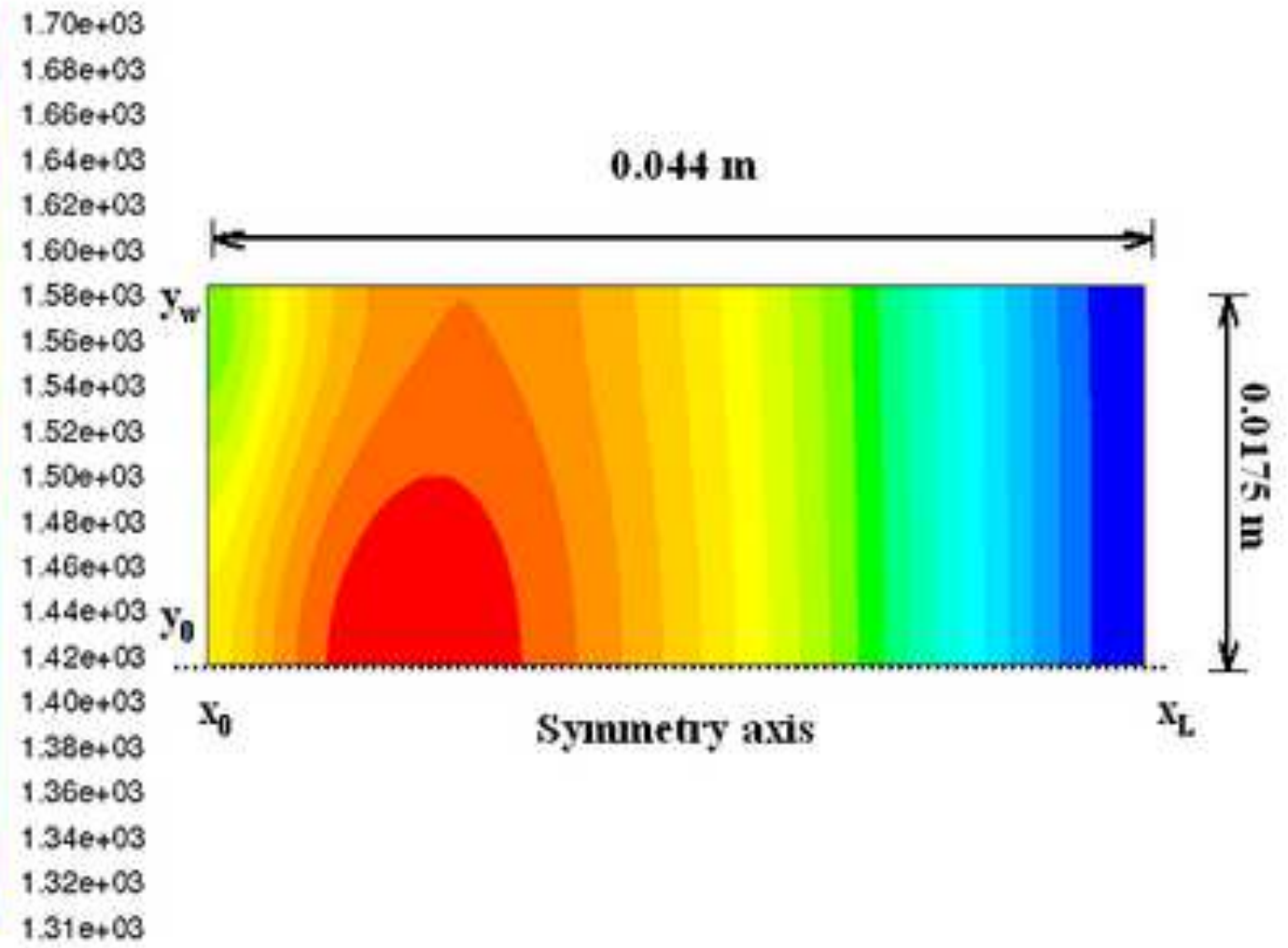




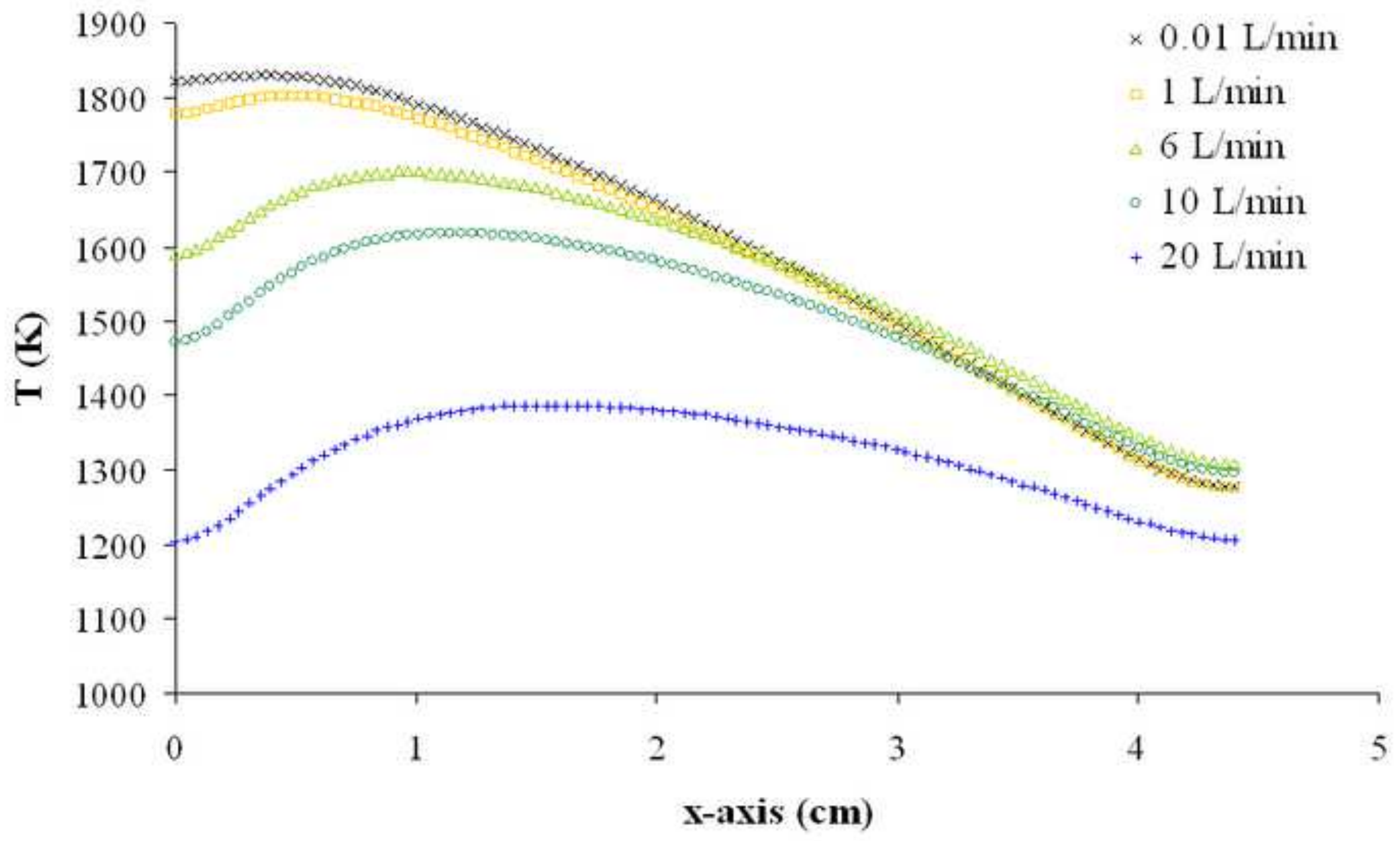




\section{T (K)}

C

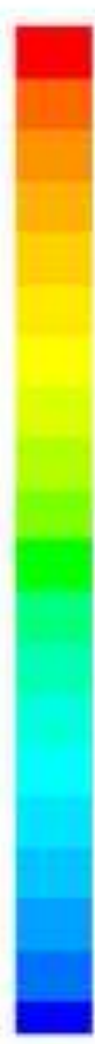

$1.67 e+03$

$1.51 \mathrm{e}+03$

$1.54 \mathrm{e}+03$

$1.47 e+03$

$1.40 \mathrm{e}+03 \quad \mathrm{y}_{\mathrm{v}}$

$1.33 e+03$

$1.26 e+03$

$1.19 e+03$

$1.12 e+03$

$1.06 \mathrm{e}+08$

$9.87 e+02$

$9.18 \mathrm{e}+02$

$8.500+02$

$7.81 \mathrm{e}+02$

$7.12 e+02$

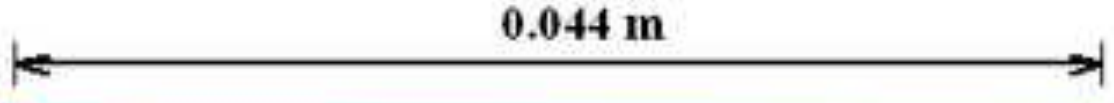

$6.44 \mathrm{e}+02$

$5.75 e+02$

$5.06 e+02$

$4.37 e+02$

$3.69 e+02$

T (K)
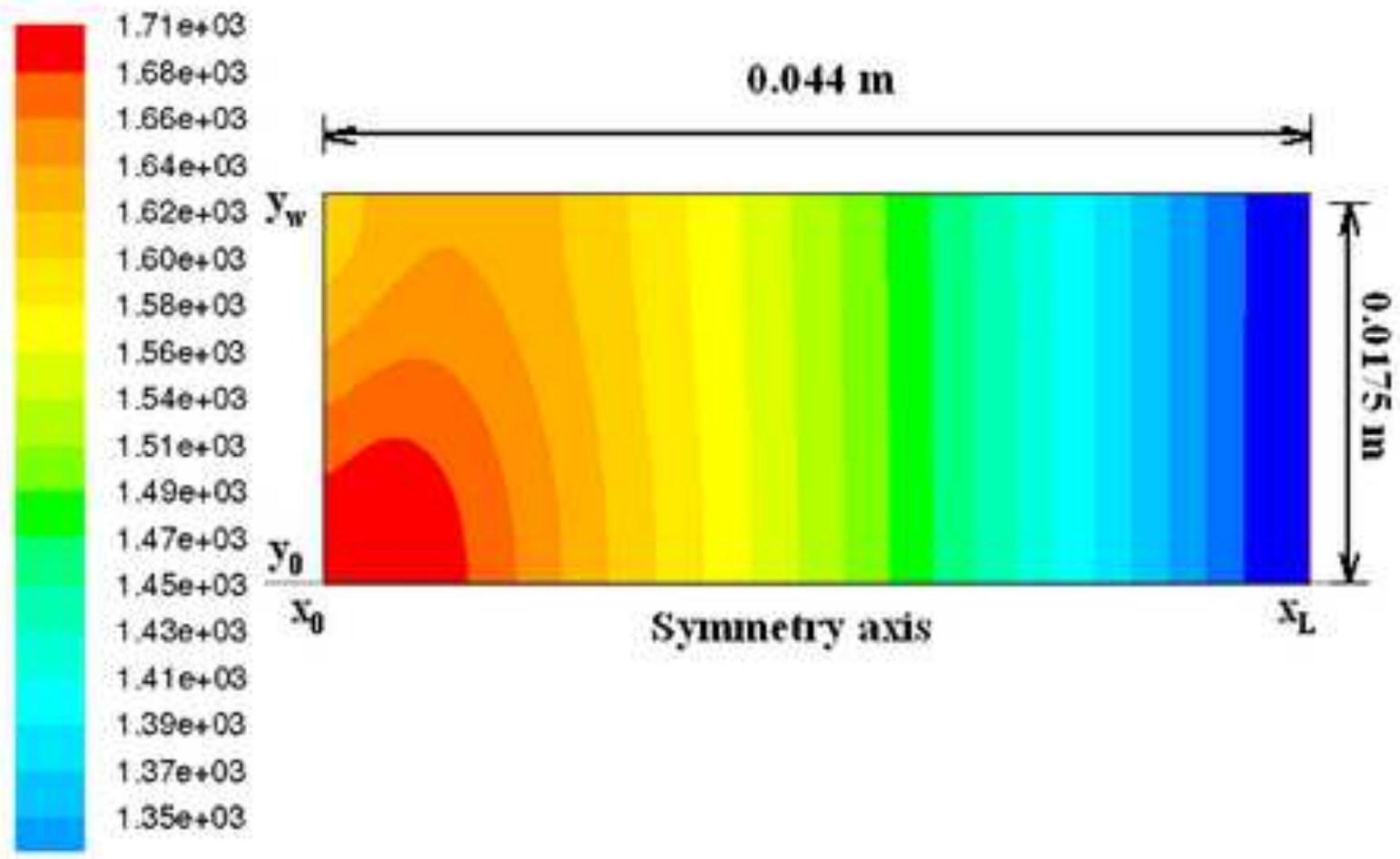

$1.35 e+03$ 


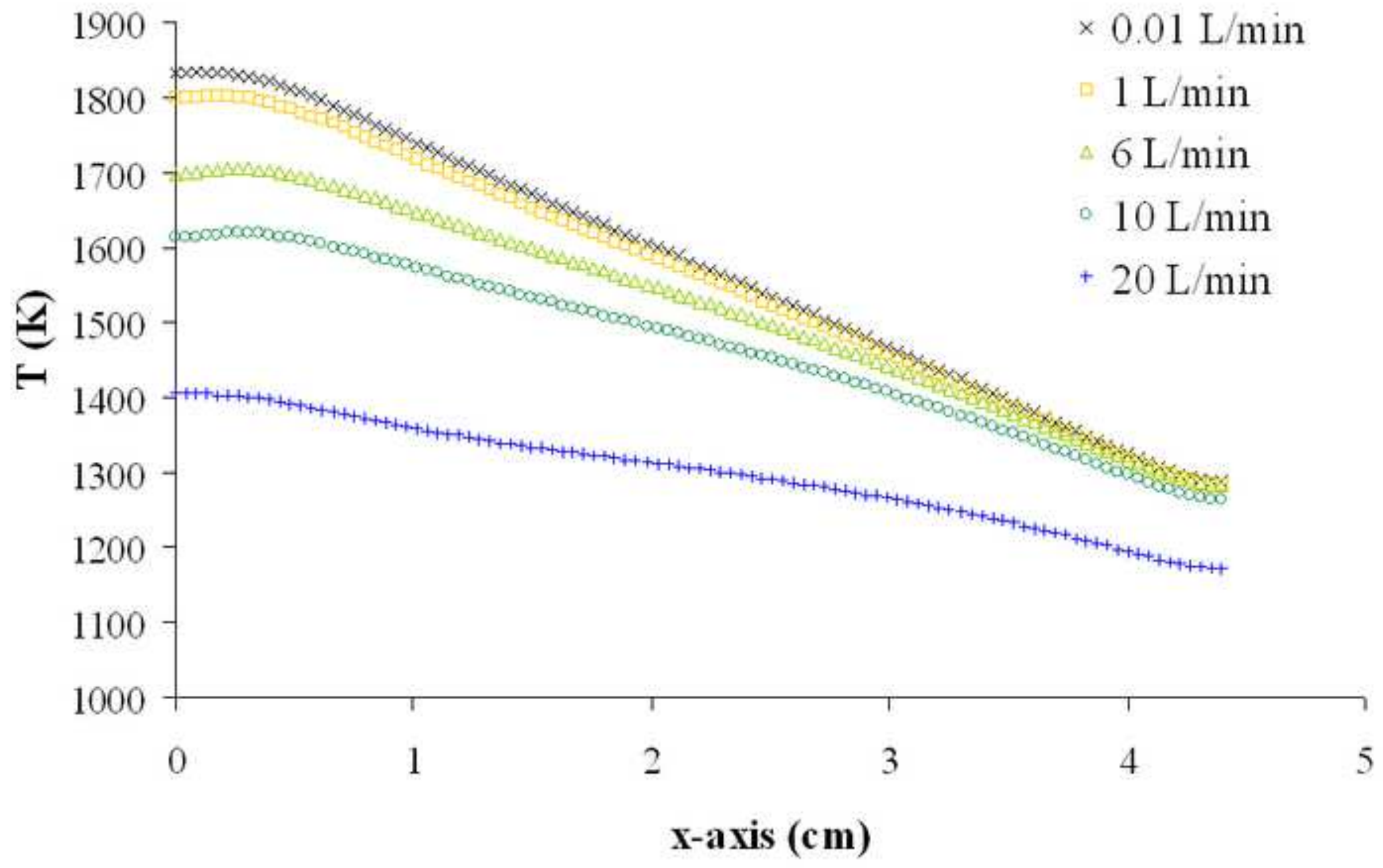


Click here to download high resolution image

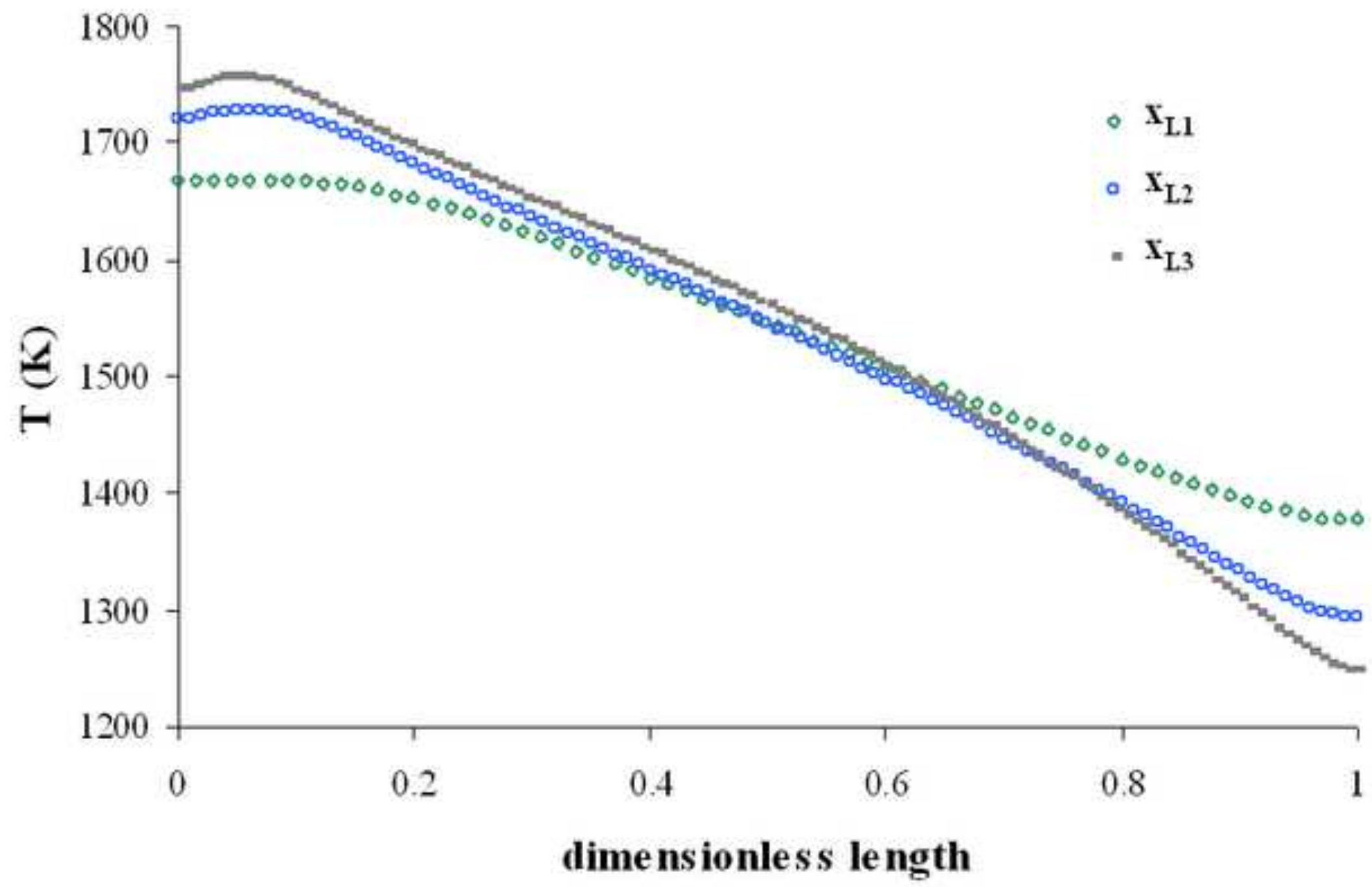




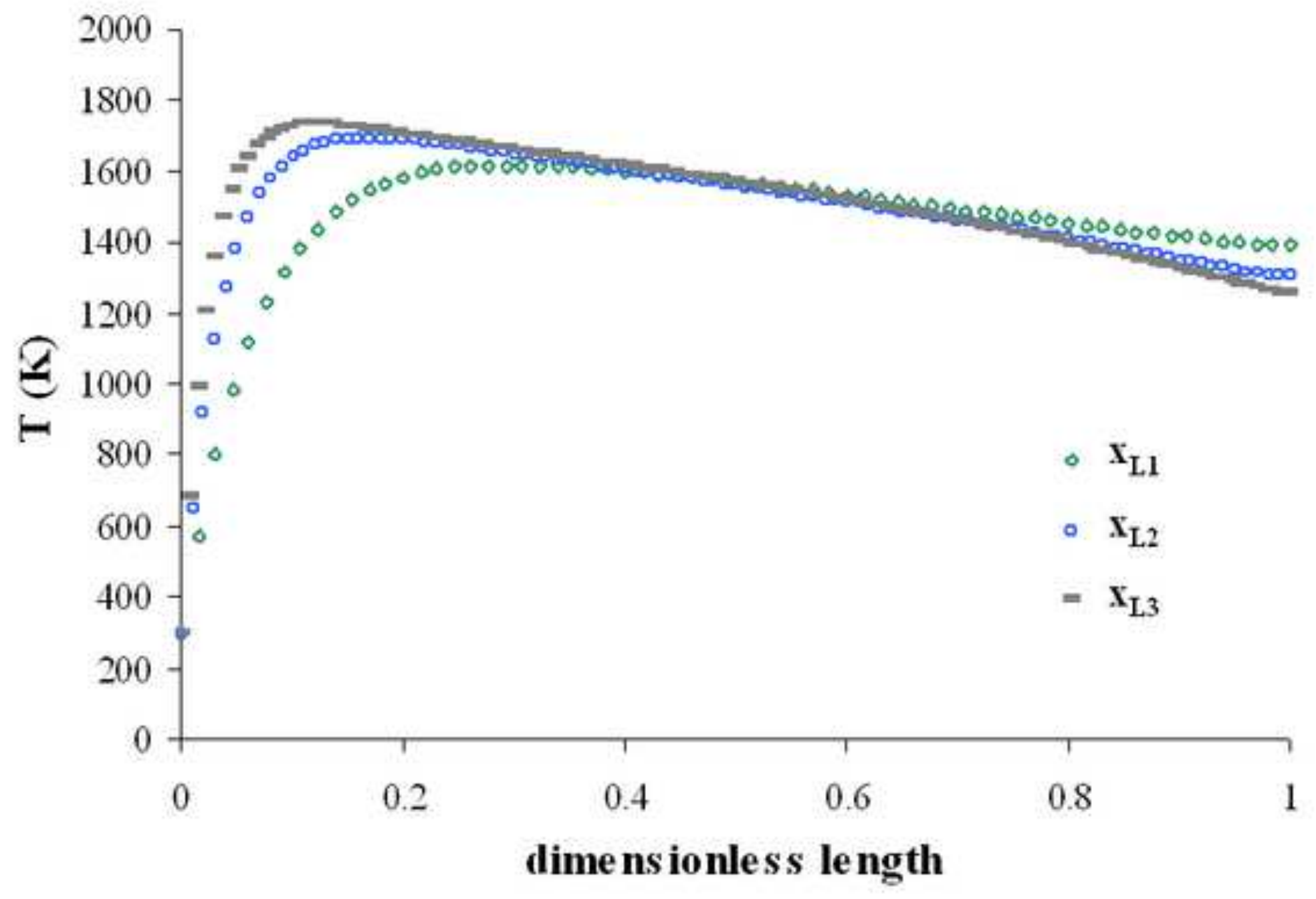




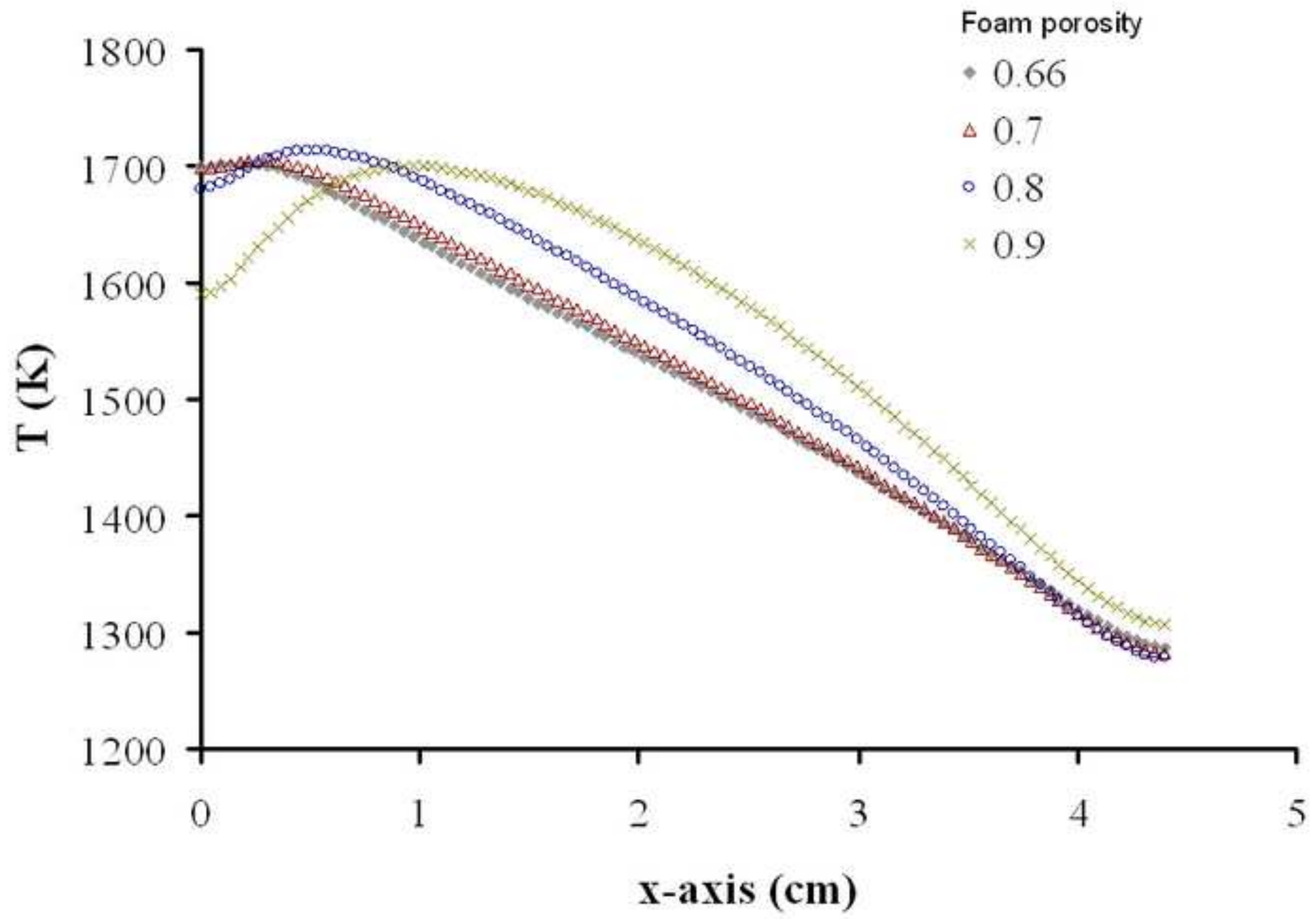




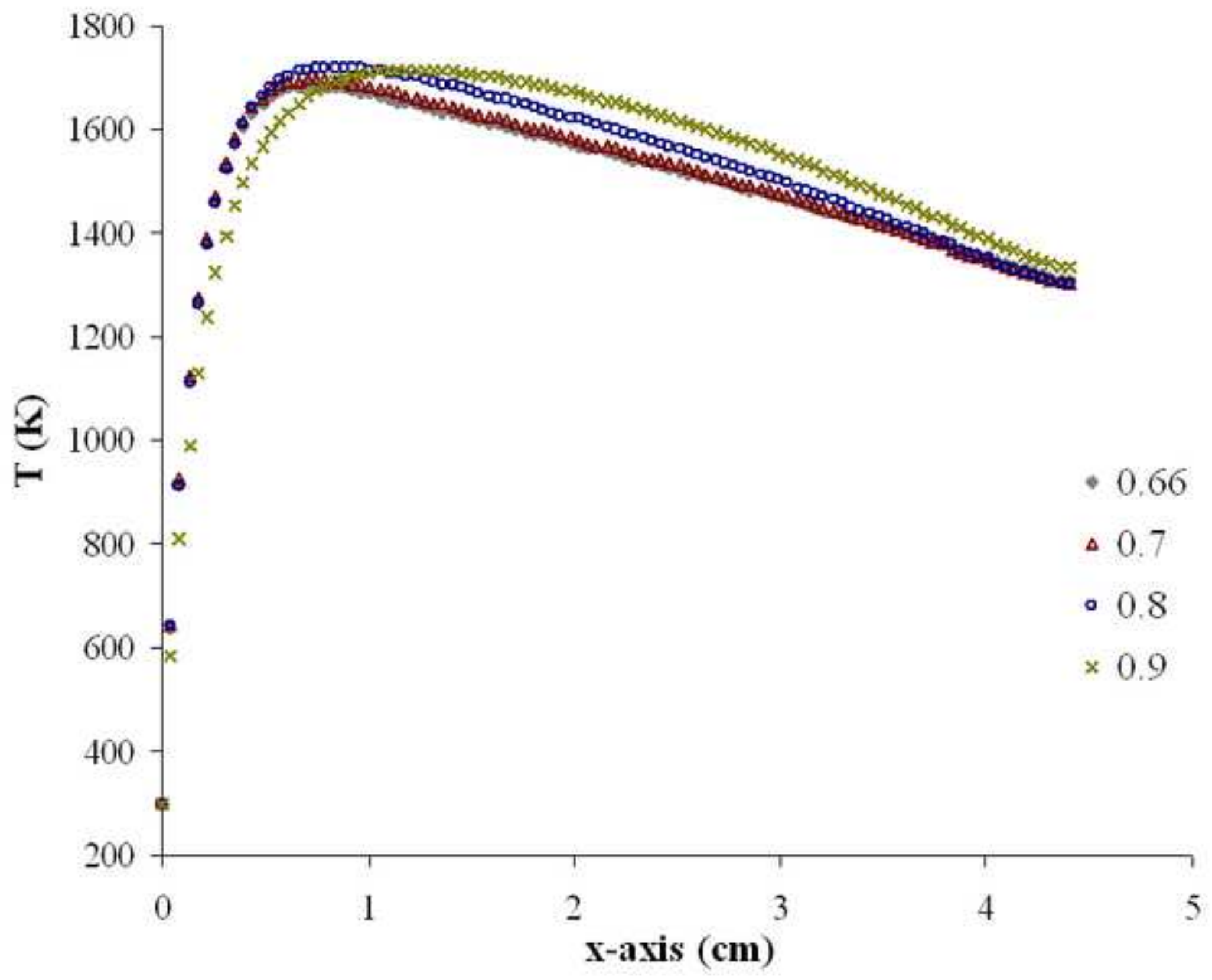




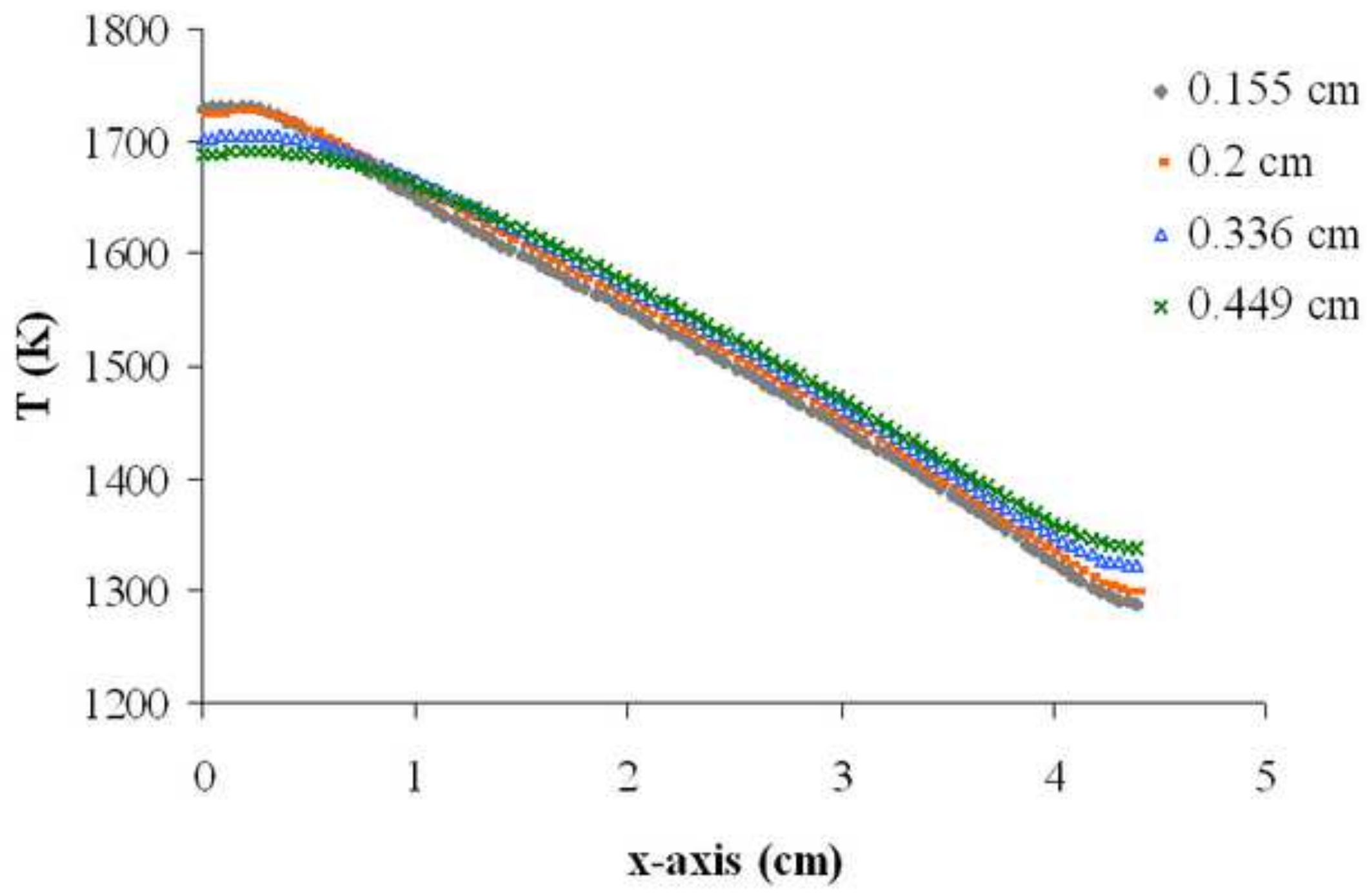




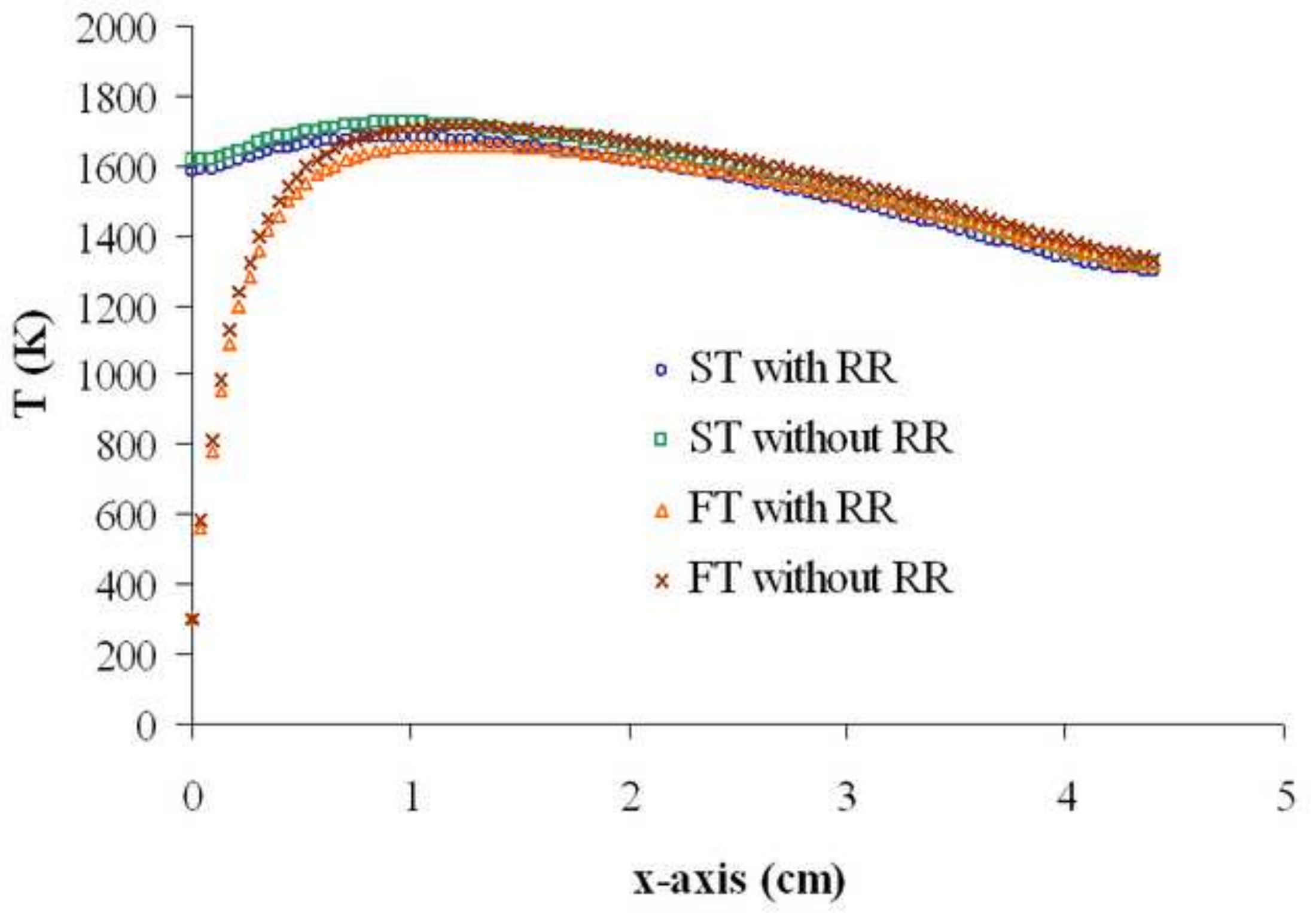




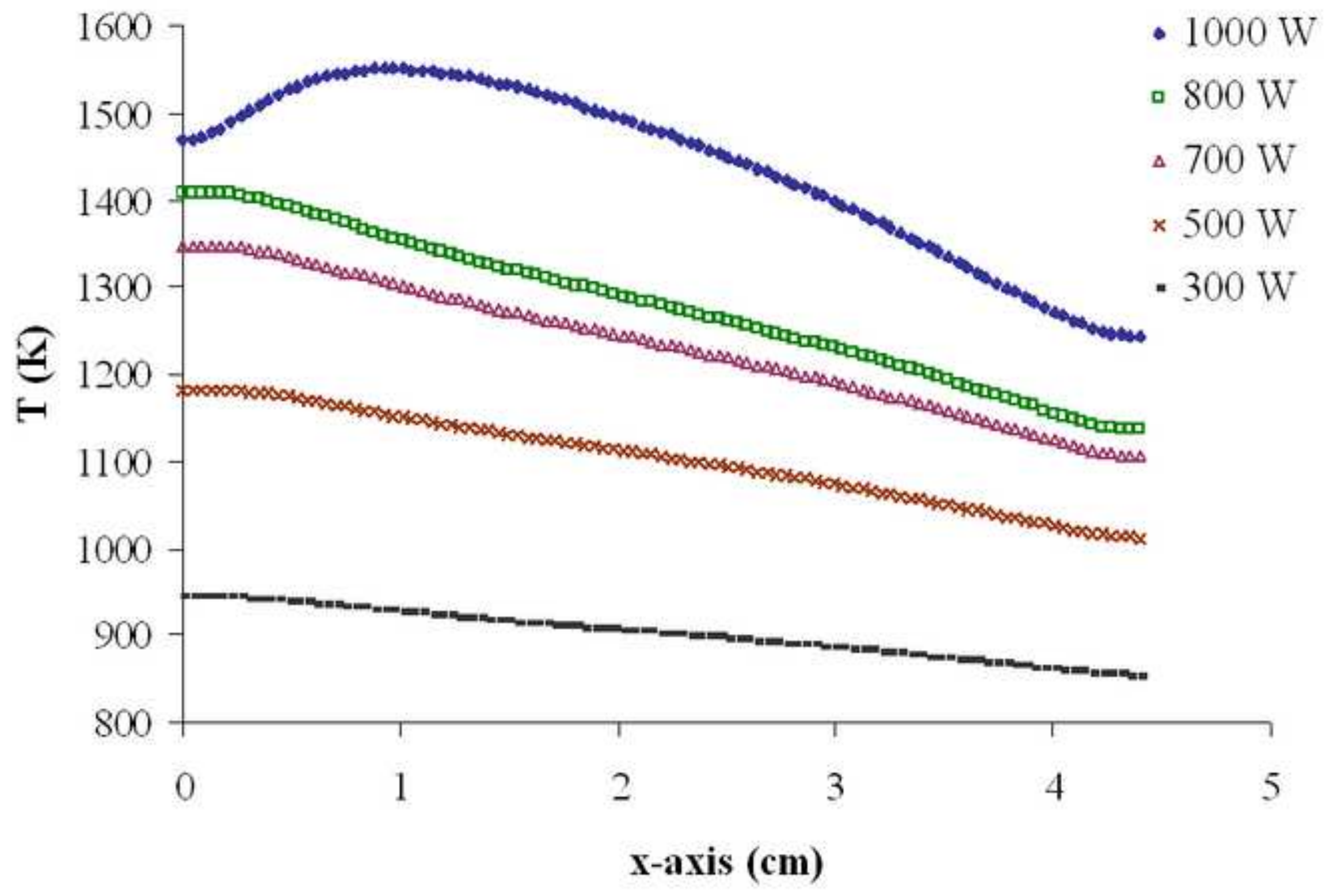




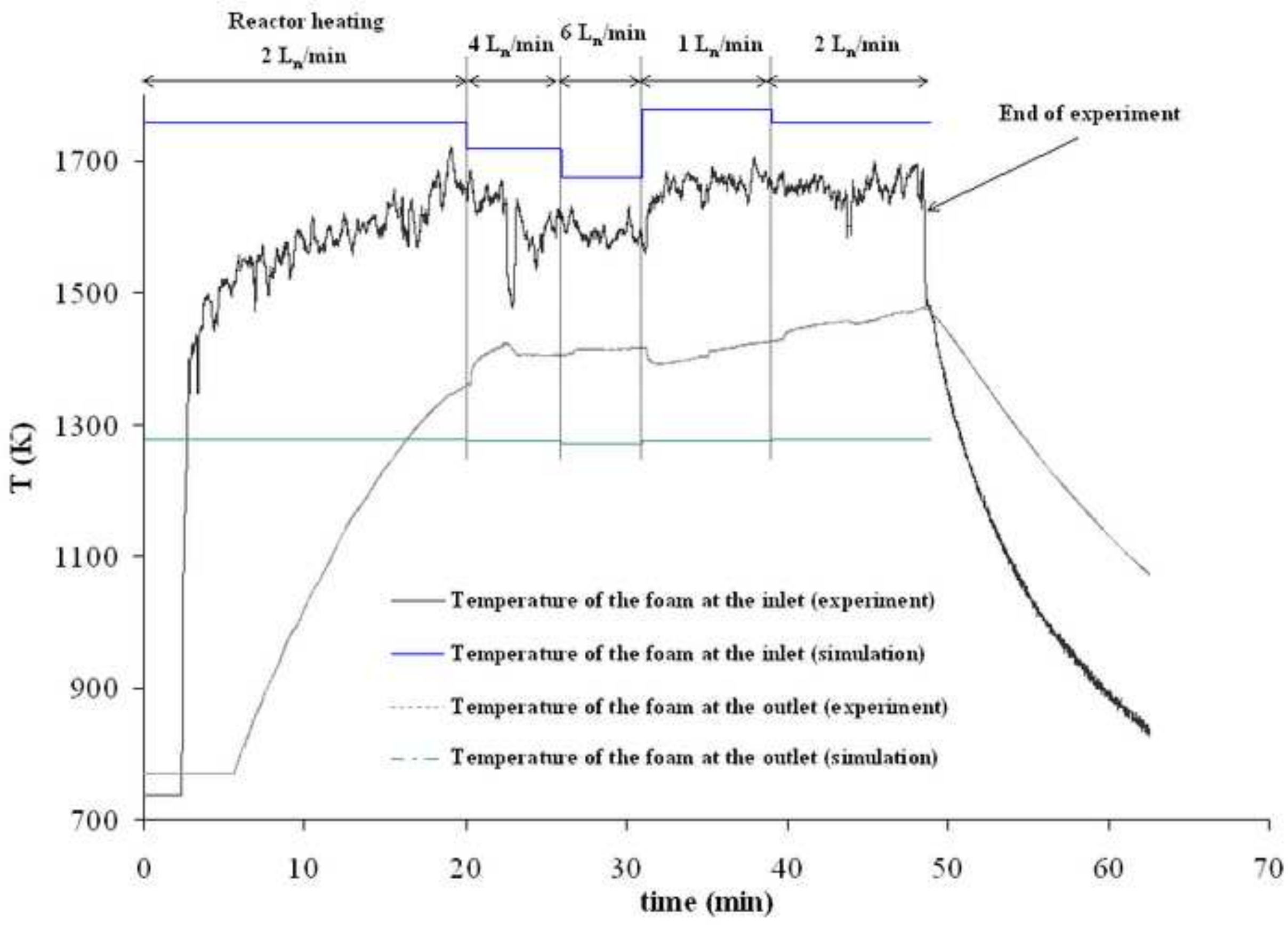

